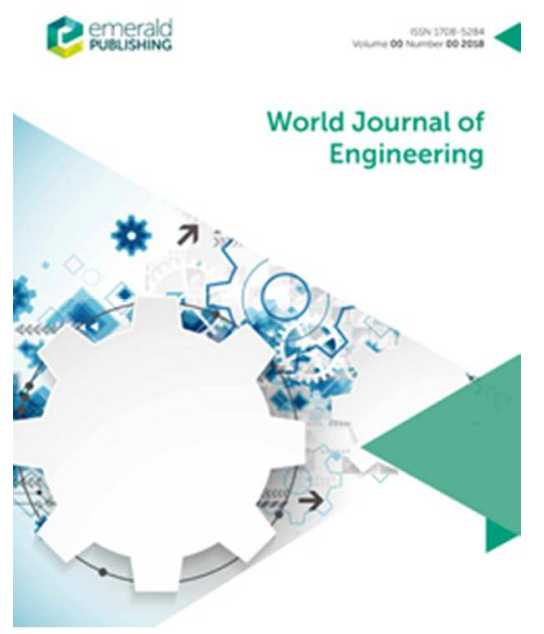

\title{
Experimental studies and theoretical models for concrete columns confined with FRP composites: A review
}

\begin{tabular}{|r|l|}
\hline Journal: & World Journal of Engineering \\
\hline Manuscript ID & WJE-01-2018-0026.R4 \\
\hline Manuscript Type: & Review Paper \\
\hline Keywords: & $\begin{array}{l}\text { FRP composites, circular and non-circular columns, confinement, Stress- } \\
\text { strain model }\end{array}$ \\
\hline \multicolumn{2}{|l}{} \\
\hline
\end{tabular}




\title{
Experimental studies and theoretical models for concrete columns confined with FRP composites: A review
}

\begin{abstract}
Purpose - Advanced fibre reinforced polymer (FRP) composites have been increasingly used over the last two decades for strengthening, upgrading, and restoring degraded civil engineering infrastructure. Substantial experimental investigations have been conducted in recent years to understand the compressive behaviour of FRP-confined concrete columns. A considerable number of confinement models to predict the compressive behaviour of FRP strengthened concrete columns have been developed from the results of these experimental investigations. The purpose of this paper is to present a comprehensive review of experimental investigations and theoretical models of circular and non-circular concrete columns confined with FRP reinforcement.

Design/methodology/approach - The paper reviews previous experimental test results on circular and non-circular concrete columns confined with FRP reinforcement under concentric and eccentric loading conditions and highlights the behaviour and mechanics of FRP confinement in these columns. The paper also reviews existing confinement models for concrete columns confined with FRP composites in both circular and non-circular sections.

Findings - This paper demonstrates that the performance and effectiveness of FRP confinement in concrete columns have been extensively investigated and proven effective in enhancing the structural performance and ductility of strengthened columns. The strength and ductility enhancement depend on the number of FRP layers, concrete compressive strength, corner radius for non-circular columns, and intensity of load eccentricity for eccentrically loaded columns. The impact of existing theoretical models and directions for future research are also presented.

Originality/value - Potential researchers will gain insight into existing experimental and theoretical studies and future research directions.
\end{abstract}

Keywords FRP composites, circular and non-circular columns, confinement, stress-strain model

Paper type Literature review

\section{INTRODUCTION}

Over the last three decades, the application of advanced composite materials as external reinforcement for strengthening and retrofitting existing civil engineering infrastructure has received significant research attention. Conventional retrofitting techniques, including concrete and steel jacketing, have been used extensively for the repair and rehabilitation of reinforced concrete (RC) structures. Several researchers have investigated the influence of these jacketing methods on the compressive behaviour of RC columns and found that they are useful in enhancing the performance of 
these columns (Bousias et al., 2006; Julio and Branco, 2008; Bousias et al., 2007; Vandoros and Dritsos, 2006; Choi et al., 2013; Xiao and Wu, 2003; Campione, 2012; Kaish et al., 2012; GarzónRoca et al., 2011; Lai and Ho, 2015; Vandoros and Dritsos, 2008; Kaish et al., 2013). Bousias et al. (2006) investigated the seismic behaviour of rectangular concrete columns retrofitted with RC jacketing and fibre reinforced polymer (FRP) wrapping under cyclic loadings. The results of the investigation show that concrete columns retrofitted with RC external jacketing experience better performance in cyclic deformation capacity than FRP-wrapped concrete columns. Vandoros and Dritsos (2006) studied the influence of interface treatment methods of concrete jacketing, such as roughening the surface of the original column, using steel dowels, and roughening the surface combined with steel dowels, on the behaviour of strengthened concrete columns under displacementcontrolled earthquake simulation loading. The results confirm that the different interface treatment procedures for connecting the jacket to the original column could significantly affect the modes of failure and crack patterns of strengthened columns. The results also show that strengthened RC columns with combined roughening and dowels experience the best performance in strength, deformation capacity, and energy dissipation capacity. Choi et al. (2013) investigated the effects of steel jacketing on the bond strength of concrete and the lateral effectiveness of circular RC columns. Their study indicated that steel jacketing could convert splitting bond failure to pull-out bond failure as well as enhancing concrete bond strength. Moreover, they found that the steel jackets can delay yielding of longitudinal steel reinforcement, hence preventing spalling of concrete, which resulted in increased ultimate drift and displacement ductility of the confined RC columns. Regardless of their significant advantages in regard to strength and ductility enhancement, these jacketing systems also have some inherent shortcomings, including that they are labour intensive and time-consuming and could possibly increase the cross-sectional area of structural members. FRP composites have been used effectively in recent years as alternative materials for rehabilitating, strengthening, and upgrading damaged RC structures due to their superior tensile strength, corrosion resistance, durability, and light weight compared to steel jacketing (Hollaway and Teng, 2008; Teng et al., 2002; Hollaway, 2010). Several experimental studies have proven that FRP wrapping of RC columns is an effective means of enhancing their strength and ductility as it provides confinement to the concrete core (Ozbakkaloglu and Oehlers, 2008; Moshiri et al., 2015; Vincent and Ozbakkaloglu, 2014; Mirmiran et al., 1998; Pessiki et al., 2001; Chaallal et al., 2003; Chaallal et al., 2000; Sezen and Miller, 2011; Ilki et al., 2008; Alecci et al., 2014; Ilki and Kumbasar, 2003; Wang et al., 2017; Sheikh et al., 2007; Silva and Rodrigues, 2006; Rodrigues and Silva, 2001; Rodrigues and Silva, 2001; Cui and Sheikh, 2010b; Masia et al., 2004; Lam and Teng, 2004; Matthys, 2000; Parghi and Alam, 2018).

This paper presents a comprehensive review of previous experimental investigations into and confinement models of FRP-confined concrete columns in both circular and non-circular cross- 
sections subjected to a concentric and eccentric load. The study begins by reviewing the available experimental research studies on such columns and subsequently highlights the behaviour and mechanics of FRP confinement in circular and non-circular concrete columns. Finally, the paper reviews stress-strain models that have been proposed to predict the strength and axial strain of concrete columns confined by FRP composites in circular and non-circular cross-sections.

\section{EXPERIMENTAL INVESTIGATIONS}

\subsection{Axially Loaded FRP-Confined Circular Concrete Columns}

Researchers have conducted numerous empirical studies to assess the performance of circular concrete columns confined by FRP composites under axial loads. Mirmiran et al. (1998) investigated the influence of different test parameters on the behaviour of FRP-confined concrete columns subjected to axial loading. These test parameters included the type of concrete cross-section, length-todiameter ratio, and adhesive bond. To examine the influence of concrete cross-sectional shape, the researchers tested a series of 12 square concrete columns with a $152.5 \mathrm{~mm} \times 152.5 \mathrm{~mm}$ cross-section and height of $305 \mathrm{~mm}$, and thirty $152.5 \mathrm{~mm} \times 305 \mathrm{~mm}$ cylindrical specimens. The square columns had a corner radius of $6.35 \mathrm{~mm}$. Unidirectional E-glass fibre tubes and polyester resin were used to confine all the concrete column specimens. The FRP tubes had a varying thickness of 1.45, 2.21, and $2.97 \mathrm{~mm}$. The results showed that the glass fibre reinforced polymer (GFRP) confinement in the non-circular section was insufficient in restraining the concrete in the core compared to the uniformly confined circular concrete columns. Concerning the effect of GFRP confinement in non-circular concrete columns, the authors introduced a modified confinement ratio (MCR) given by:

$$
\begin{aligned}
& M C R=\left(\frac{2 R}{D}\right) \frac{f_{l}}{f_{c o}^{\prime}} \\
& f_{l}=\frac{2 f_{f r p} t_{f r p}}{D}
\end{aligned}
$$

where $D$ is the internal dimension of the tube, $R$ is the corner radius, $f_{l}$ is the confinement pressure, $f_{f r p}$ and $t_{\text {frp }}$ are the hoop strength of FRP tube and jacket thickness, and $\frac{f_{l}}{f_{c o}^{\prime}}$ is the confinement ratio for the equivalent circular section. Moreover, the results confirmed that no strengthening is expected for an $M C R<15 \%$ because of the insufficient FRP confinement of the concrete core in non-circular sections. The authors suggested that rounding sharp corners could improve the effectiveness of the GFRP jacket and concluded that the gain in axial stress and strain of the strengthened columns depends on FRP jacket strength and stiffness.

Berthet et al. (2005) investigated the compressive behaviour of axially loaded short cylindrical concrete columns confined with carbon and glass fabrics. The parameters investigated include compressive strength of concrete, number of FRP layers, and type of FRP reinforcement. In this study, five grades of concrete were used to prepare the concrete cylinders $(20 \mathrm{MPa}, 40 \mathrm{MPa}, 50 \mathrm{MPa}, 100 \mathrm{MPa}$, 
and 200MPa). Three concrete grade specimens were $160 \mathrm{~mm}$ in diameter and $320 \mathrm{~mm}$ in height, and two were $70 \mathrm{~mm}$ in diameter and $140 \mathrm{~mm}$ in height. The cylindrical concrete columns were wrapped with high tensile strength carbon fibre reinforced polymer (CFRP) and GFRP reinforcements. The results demonstrated a significant increase in ultimate axial strength and strain due to an increased number of FRP layers. The ultimate capacity of strengthened concrete cylinders was also found to be dependent on confinement pressure and concrete strength. Furthermore, the study concluded that the mechanical confinement efficiency of FRP wraps decreased to about $15 \%$ and $25 \%$ due to the increase in the strength of the concrete core.

Matthys et al. (2006) studied the behaviour of large-scale FRP-confined cylindrical concrete columns subjected to axial loads. They prepared a series of six large-scale RC cylinders with a diameter of $400 \mathrm{~mm}$, height of $2000 \mathrm{~mm}$, and a concrete compressive strength of $36.1 \mathrm{MPa}$. The RC columns were strengthened with CFRP sheets, GFRP fabrics, and hybrid fibre reinforced polymer (HFRP) fabrics. The results showed that FRP confinement is an efficient means of enhancing the strength and ductility of RC columns. However, strength and ductility gain depend on the stiffness and tensile strength of the FRP fabric material. The authors also reported that the tensile strain of FRP reinforcement was much higher than the effective hoop failure strain considering the linear elastic behaviour of the FRP composites. Figure-1 illustrates the mechanism of FRP rupture experienced by the strengthened columns.

Almusallam (2007) studied the performance of axially loaded concrete cylinders confined with E-glass fabrics material having a tensile strength of 540MPa and elastic modulus of $27 \mathrm{GPa}$. The plain concrete columns had a dimension of $150 \mathrm{~mm} \times 300 \mathrm{~mm}$ and concrete strength ranging from 40 to $100 \mathrm{MPa}$. The findings show that GFRP laminates, when used as external reinforcement to concrete cylinders, could enhance the axial and lateral strength of concrete cylinders up to $110 \%$ and provide ductility enhancement. Moreover, the author confirmed that the strengthened cylindrical columns with normal concrete strength experienced a significant percentage gain in ultimate strength compared to the wrapped cylinders with high-strength concrete, as shown in Figure-2.

Sheikh et al. (2007) investigated the behaviour of large-scale concrete-filled prefabricated glass FRP shells subjected to a concentric load. A series of 17 cylindrical concrete columns with a diameter of $356 \mathrm{~mm}$ and height of $1524 \mathrm{~mm}$ were fabricated and tested. The column specimens were prepared with concrete cured for 28 days and compressive strength of $30 \mathrm{MPa}$. The effect of test variables, including number of GFRP layers, fibre orientation, and amount of longitudinal and lateral steel hoops, was examined. It was found that the prefabricated GFRP shells could be used as permanent formwork as well as an effective confinement reinforcement for concrete columns. Moreover, the results also revealed that the cylindrical columns with inclined GFRP shells experienced more ductile behaviour compared to columns with longitudinal or lateral GFRP shells. 
Sezen and Miller (2011) investigated the effects of jacketing systems, including FRP wrap, steel jackets, concrete jackets with welded wire fabric, concrete jackets strengthened with rebar, and concrete jackets with prefabricated cage system (PCS) reinforcement (see Figures-3 and 4), on the behaviour of RC circular columns. They cast a series of $15 \mathrm{RC}$ columns with a height of $762 \mathrm{~mm}$ and a diameter of $152 \mathrm{~mm}$ and subjected to axial loading. The results demonstrate that RC columns confined by concrete jackets reinforced with rebar sustained significant axial load before failure and experienced a sudden decline in load-carrying capacity after the collapse. The results of the investigation also confirm that FRP wrapping was very efficient, improving the axial strength of the RC cylinders by $140 \%$ without an increase in section size as with other jacketing systems.

Toutanji and Balaguru (1998) conducted durability tests to investigate the behaviour of FRPwrapped concrete cylinders exposed to wet-dry and freeze-thaw conditions and subjected to uniaxial compressive loading to failure. The parameters studied include type of FRP and environmental exposure conditions. The specimens consisted of 24 concrete cylinders measuring $76 \mathrm{~mm}$ in diameter and $305 \mathrm{~mm}$ in height and grouped into three groups with six specimens each, with two specimens confined with CFRP reinforcement, two confined with GFRP reinforcement, and two samples used as control specimens. Prior to compression testing, the specimens in the first group were subjected to room temperature, specimens in the second group were subjected to wet-dry cycling, and the remaining specimens were subjected to freeze-thaw cycling. The results show that exposure to wet-dry cycling had no significant effect on strength and ductility gains of the CFRP-confined columns but led to an up to $10 \%$ decrease in strength and ductility of GFRP-confined concrete cylinders without influencing the stiffness. The experimental investigation also indicated that freeze-thaw exposure could result in a significant decrease in both strength and ductility of CFRP and GFRP strengthened columns. Moreover, the results show that the stiffness of concrete cylinders wrapped with CFRP and GFRP reinforcements is not affected by freeze-thaw environmental conditions.

El-Hacha et al. (2010) studied the influence of extreme temperature variations on the behaviour of axially loaded plain concrete cylinders confined with FRP reinforcement. The authors tested 36 plain concrete cylinders measuring $150 \mathrm{~mm}$ in diameter and $300 \mathrm{~mm}$ in height. Nine of the concrete cylinders were used as control specimens, and the remaining columns were strengthened with two layers of CFRP wrap. The strengthened concrete columns were exposed to three different temperature conditions, namely elevated temperatures $\left(45^{\circ} \mathrm{C}\right)$, heating and cooling cycles $\left(23-45^{\circ} \mathrm{C}\right)$ and prolong heating $\left(45^{\circ} \mathrm{C}\right)$. However, the strengthened concrete columns exposed to heating and cooling cycles were further exposed to freezing and thawing cycles, and the remaining columns were immersed in pure or salt water for 23 days. It was found that the strength of the CFRP-confined concrete columns is not affected by extreme exposure to elevated temperatures of about $45^{\circ} \mathrm{C}$. 
Cui and Sheikh (2010b) conducted an experimental investigation to evaluate the influence of various parameters, including concrete strength, type of FRP, number of FRP layers, and concrete condition before FRP bonding, on the behaviour of axially loaded normal, medium, and high-strength concrete confined with FRP reinforcement. The authors tested 112 cylindrical columns of which 88 were wrapped with FRP and the remaining 24 were unwrapped. The cylindrical specimens had a diameter of $152 \mathrm{~mm}$ and a height of $305 \mathrm{~mm}$ with carbon and glass fabrics as the externally bonded reinforcement. The results of the findings show that the strength enhancement provided by the confining FRP is independent of the amount of FRP when high-modulus FRP is used. However, a minimum number of FRP layers are required to achieve strength enhancement when FRP with a low modulus is used. This minimum requirement increases with increasing unconfined concrete strength and decreases with FRP stiffness. The increase in the load-carrying capacity of the strengthened columns increases proportionally with the number of FRP layers and is more prominent in columns with low-grade concrete.

Other investigations include Vincent and Ozbakkaloglu (2014), who studied the behaviour of high-strength concrete (HSC) circular columns confined by prestressed aramid FRP tubes under axial loading. The researchers concluded that prestressed AFRP confinement could improve the toughness of strengthened concrete cylinders, leading to a significant enhancement in ductility and energy absorption. Silva and Rodrigues (2006) studied the influence of size and relative stiffness on the compressive failure of cylindrical concrete columns wrapped with GFRP reinforcement. The authors concluded that increasing the section diameter of the concrete cylinders resulted in a significant reduction in the compressive strength of the GFRP-wrapped columns if the thickness of the GFRP shell is not increased.

\subsection{Axially Loaded FRP-Confined Non-Circular Concrete Columns}

Chaallal et al. (2003) studied the behaviour of small rectangular and square concrete columns confined with CFRP wraps under axial loads and found a significant increase in strength and ductility of the strengthened columns. However, the strength and ductility enhancement depends on stiffness of the FRP reinforcement and is more significant in columns with lower unconfined concrete compressive strength.

Al-Salloum (2007) conducted an experimental investigation on the performance of CFRPjacketed square concrete columns under axial loading. The concrete section was varied from square to circular to determine the effect of the corner radius of a section. The results show that concrete cylinders confined with CFRP exhibited better performance, followed by CFRP-confined concrete columns with a square cross-section and corner radius of $50 \mathrm{~mm}, 38 \mathrm{~mm}, 25 \mathrm{~mm}$, and $5 \mathrm{~mm}$. The strengthened square concrete columns failed at or near section corners. Other researchers (Wang and 
Wu, 2008; Triantafyllou et al., 2015; Hosseinpour and Abbasnia, 2014) have also reported a similar failure mechanism.

Ozbakkaloglu and Oehlers (2008) investigated the behaviour of square and rectangular concrete columns confined by CFRP tubes under concentric loading. The results show that CFRP confinement substantially improved the strength and ductility of both square and rectangular concrete columns, with higher performance in square columns. The results also confirm that the effectiveness of CFRP jackets decreased with increasing unconfined concrete strength.

Wang and $\mathrm{Wu}$ (2008) investigated the performance of normal and HSC columns confined with CFRP reinforcement under axial loading. The concrete columns had a concrete compressive strength of $30 \mathrm{MPa}$ and 50MPa. The tested specimens include 108 short square concrete columns with a $150 \mathrm{~mm} \times 150 \mathrm{~mm}$ cross-section and height of $300 \mathrm{~mm}$. The columns had varying corner radii of 0,15 , $30,45,60$, and $75 \mathrm{~mm}$ and were wrapped with zero, one and two layers of CFRP wrap. The parameters investigated included the corner radius of specimens, thickness of the CFRP jacket, and strength of concrete. It was found that strength enhancement in CFRP-confined square concrete columns depends on the corner radius of the cross-section. The results also indicate that CFRP confinement in square columns with sharp corners is insignificant in improving column strength but significant in enhancing ductility. Similarly, Benzaid and Mesbah (2014) investigated the behaviour of short CFRP-wrapped circular and square RC columns under axial loading. The column specimens had different degrees of CFRP wrapping and concrete strength of $26 \mathrm{MPa}$ (normal strength), 50MPa (medium strength), or $62 \mathrm{MPa}$ (high strength). The researchers observed that the strengthened columns experienced a decline in confinement effectiveness due to increased unconfined concrete strength. Furthermore, it was found that CFRP confinement in circular concrete columns resulted in better efficiency compared to that of square concrete columns.

\subsection{Eccentrically Loaded FRP-Confined Circular Columns}

Some researchers have investigated the behaviour of concrete columns confined by FRP reinforcement under eccentric loading. However, most of these investigations have focused predominantly on circular concrete columns (Ghali et al., 2003; Li and Hadi, 2003; Hadi and Li, 2004; Hadi, 2009; Wu and Jiang, 2013; Siddiqui et al., 2014), with only limited studies available on eccentrically loaded FRP-confined non-circular concrete columns. Li and Hadi (2003) studied the behaviour of eccentrically loaded CFRP and GFRP wrapped circular concrete columns. To achieve a load eccentricity of $42.5 \mathrm{~mm}$ and prevent premature failure, the authors introduced large end corbels in the column specimens. The results show that FRP wrapping slightly improves the performance of eccentrically loaded strengthened columns because eccentric loading results in axial and bending effects. Subsequently, Ghali et al. (2003) conducted a comprehensive experimental study on smallscale CFRP-confined cylindrical concrete columns subjected to eccentric loading. The circular 
concrete columns had a cross-sectional diameter of $150 \mathrm{~mm}$ with heights of $610 \mathrm{~mm}, 915 \mathrm{~mm}$, and $1220 \mathrm{~mm}$. The column specimens were tested with load eccentricities of $0,7.5$, and $15 \mathrm{~mm}$. The results show that an increase in load eccentricity resulted in a significant decrease in ultimate load-carrying capacity of the strengthened concrete columns, namely $26 \%$ and $70 \%$ for CFRP-confined concrete columns with height to diameter (H/D) ratios of 4 and 8. From Figure-5, it is evident that the loadcarrying capacity of the strengthened columns is very sensitive to the magnitude of the load eccentricity.

Hadi and Li (2004) investigated the effect of galvanised steel straps and FRP wrapping on the performance of concentrically and eccentrically loaded circular concrete columns. The tested columns had concrete compressive strength of 73.62MPa for columns subjected to concentric loading and $51 \mathrm{MPa}$ for columns subjected to eccentric loading. The authors concluded that external strengthening of columns by FRP composites provides the highest amount of confinement and that benefit can be enhanced by applying multiple layers of FRP composite. Hadi (2009) continued the investigation on 12 RC columns with circular cross-sections strengthened with different degrees of CFRP confinement (zero, one, or three layers). The strengthened columns were tested under varying load eccentricities of $0 \mathrm{~mm}, 25 \mathrm{~mm}$, and $50 \mathrm{~mm}$ and assigned to one of four groups according to the strengthening scheme. The first group consisted of RC columns without CFRP confinement. The second group had three layers of CFRP reinforcement used to confine the columns. The third group columns were made of RC incorporated with steel fibres with no CFRP wrapping. Lastly, the fourth group specimens were similar to the specimens in the third group but were confined with three layers of CFRP reinforcement. The results show that the eccentrically loaded RC columns experienced a decrease in ultimate capacity due to the increase in load eccentricity. The results also confirm that the presence of steel fibre in concrete did not significantly strengthen the columns confined with CFRP jackets. Furthermore, according to the author, both steel fibre and CFRP confinement were effective in improving the ductility of the CFRP-confined RC columns. Figure-6 shows typical loading caps for applying eccentric loads.

Wu and Jiang (2013) investigated the stress-strain behaviour of eccentrically loaded cylindrical concrete columns confined by CFRP jackets. A total of 36 circular concrete columns measuring $150 \mathrm{~mm}$ in diameter and $300 \mathrm{~mm}$ in height were cast. The circular columns were wrapped with CFRP jackets using zero, one, and two layers. The strengthened columns were subjected to load eccentricities of $0,10,20,30,40$, and $50 \mathrm{~mm}$. An increase in load eccentricity led to a decrease in the ultimate strength of the strengthened columns. It was also found that the stress distribution across the section was non-uniform due to the presence of eccentric loading. Consequently, the authors argue that it is inappropriate to use the stress-strain relationship for axially loaded columns for developing the relationship for eccentrically loaded columns because it underestimates the stiffness and strength 
of columns under eccentric loading. They also found that the strain at failure of the strengthened columns was higher in columns under eccentric load than in axially loaded columns of the same level of confinement.

Siddiqui et al. (2014) investigated the influence of hoop and longitudinal FRP confinement on the performance of circular RC columns under eccentric loading. A series of 12 cylindrical RC columns specimens measuring $150 \mathrm{~mm}$ in diameter with varying heights of $600 \mathrm{~mm}, 900 \mathrm{~mm}$, and $1200 \mathrm{~mm}$. Each group consisted of four circular RC columns; one was considered a control specimen and the remaining three had different degrees of FRP confinement. One layer of hoop CFRP sheet was used to confine one column specimen, and the remaining two columns were confined with two and four layers of longitudinal CFRP reinforcements, respectively, and one layer of hoop CFRP sheet. All the columns were subjected to eccentric loadings using $25 \mathrm{~mm}$ load eccentricity. The experimental results show that the hoop CFRP wraps substantially increased the strength and ductility of the strengthened RC columns because they confined the concrete and provided lateral support to the longitudinal fibres.

\subsection{Eccentrically Loaded FRP-Confined Non-Circular Concrete Columns}

Parvin and Wang (2001) conducted experimental and numerical studies on the influence of strain gradient in small-scale eccentrically loaded FRP-wrapped square concrete columns. The square concrete columns had a concrete cube strength of approximately $21.4 \mathrm{MPa}$ and rounded corners at the sharp edges with a radius of $8.26 \mathrm{~mm}$. A unidirectional CFRP was used to wrap the concrete columns using zero, one, and two layers. The study also investigated the influence of three different load eccentricities $(0,7.50$, and $15.20 \mathrm{~mm})$. The authors report that CFRP wrapping could substantially improve the strength and ductility of strengthened columns under eccentric loading. However, axial strain gradient due to the presence of load eccentricity resulted in a $20 \%$ decrease in CFRP retrofitting capability.

Sadeghian et al. (2010) conducted an experimental investigation of CFRP-confined rectangular RC columns subjected to eccentric loading. A series of seven large-scale RC rectangular columns with a cross-section of $200 \mathrm{~mm} \times 300 \mathrm{~mm}$, height of $1500 \mathrm{~mm}$, and end corbels $600 \mathrm{~mm}$ in height were cast. The rectangular concrete columns had an overall height of $2700 \mathrm{~mm}$, and corners of the sections had a radius of $15 \mathrm{~mm}$. The various test parameters investigated include the number of FRP layers (i.e. two, three, or five layers), fibre orientation (i.e. $0^{\circ}, 90^{\circ},+45^{\circ}$ and $-45^{\circ}$ ), and magnitude of load eccentricities of $200 \mathrm{~mm}$ and $300 \mathrm{~mm}$. The results show that the strengthened columns exhibited a significant improvement in performance compared with the unconfined columns. The application of longitudinal CFRP wrap led to bending stiffness and moment capacity enhancement but no significant improvement in curvature capabilities. Moreover, the study found that strengthened specimens with 
angle orientation exhibited a significant increase in bending stiffness, moment capacity, and deflection capacity.

Similarly, Hadi and Widiarsa (2012) investigated the influence of CFRP wrapping and different load eccentricities on the behaviour of square RC columns. They cast 16 square RC columns with a section corner radius of $34 \mathrm{~mm}$. The columns had a cross-section measuring $200 \mathrm{~mm} \times 200 \mathrm{~mm}$ and a height of $800 \mathrm{~mm}$. Twelve columns were tested under compressive loading using 0,25 , and $50 \mathrm{~mm}$ load eccentricities, and the remaining four columns were tested as beams. The columns were divided into four groups according to the wrapping scheme. The first group consisted of unwrapped RC columns, and the second group had one layer of CFRP wrap to strengthen columns. The columns in the third group were confined with three layers of CFRP reinforcement, and the columns in the fourth group had one CFRP strap in the vertical direction and two CFRP wraps in the horizontal direction. The experimental results indicate that CFRP wraps significantly improved the strength and ductility of the strengthened RC columns. Moreover, the presence of vertical CFRP straps in the strengthened RC columns significantly improved the performance of the columns.

Following Hadi and Widiarsa (2012), other similar investigations include Daugevičius et al. (2013), who studied the effects of load eccentricity on CFRP-confined rectangular RC columns. The authors tested a series of 14 rectangular RC columns with six of the column specimens strengthened with one layer of CFRP wrap. The rectangular RC columns had a cross-section of $150 \mathrm{~mm} \times 150 \mathrm{~mm}$ and height of $625 \mathrm{~mm}$. The specimens were tested eccentrically to failure using eccentricities of 0 , $30 \mathrm{~mm}$, and $45 \mathrm{~mm}$ and with eccentricity/height ratios of 0.2 and 0.3 . The results show that the ultimate capacity of the strengthened columns directly depends on the load eccentricity because an increase in load eccentricity from $0 \mathrm{~mm}$ to $45 \mathrm{~mm}$ led to an approximately $64 \%$ decrease in the ultimate capacity of the strengthened columns, as shown in Figure-7.

\section{MECHANICS OF FRP CONFINEMENT}

\subsection{FRP Confinement in Circular Concrete Columns}

In FRP-confined concrete, the externally bonded FRP reinforcement provides a passive type of confinement to the concrete core. This usually occurs due to the lateral dilation of the concrete when subjected to concentric loadings. FRP reinforcement produces tensile hoop stress because of the increasing axial stress and lateral strain. However, this tensile hoop stress is counterbalanced by a similar radial pressure, which resists the lateral dilation of the concrete (Lorenzis and Tepfers, 2003). External FRP reinforcement resists the lateral dilation of the concrete core in FRP-confined circular columns due to axial compressive stress. Figure- 8 shows a typical confining action by FRP confinement in circular concrete columns. Furthermore, the circular concrete columns confined with 
FRP reinforcement under axial compression achieved uniform confinement over the concrete crosssection. The maximum confining pressure $f_{l}$ in FRP is given by:

$$
f_{l}=\frac{2 E_{f r p} t_{f r p} \varepsilon_{f u}}{d}=\frac{\rho_{f r p} f_{f r p}}{2}
$$

where $E_{f r p}$ is the elastic modulus of FRP, $\varepsilon_{f u}$ is the ultimate tensile strain of FRP composites, $f_{f r p}$ is the ultimate tensile strength of the FRP jacket, $t_{f r p}$ is the thickness of FRP wrap, ' $d$ ' is the diameter of circular concrete section, and $\rho_{f r p}$ is the volumetric ratio of FRP for the fully wrapped circular concrete cross-section, which can be evaluated as:

$$
\rho_{f r p}=\frac{\pi d t_{f r p}}{\pi d^{2} / 4}=\frac{4 t_{f r p}}{d}
$$

\subsection{FRP Confinement in Non-Circular Concrete Columns}

In non-circular FRP-confined concrete columns, the FRP confining stress varies over the column cross-section, and only a portion of the concrete is adequately confined. These variations in confining pressure result in an excessive decrease in confinement efficiency (Mirmiran et al., 1998). Moreover, failure of FRP-confined rectangular and square concrete columns always commences at or near one of the corners and generally occurs by rupture of the FRP jacket (Al-Salloum, 2007; Benzaid and Mesbah, 2014; Youssef et al., 2007). The efficiency of FRP reinforcement can be enhanced by rounding the sharp edges of the concrete column. However, the rounded corners of the concrete crosssection are limited to small values due to the presence of inner steel rebar. Prior investigations of steelconfined concrete columns (Park and Paulay, 1975; Mander et al., 1988; Cusson and Paultre, 1995) have led to the simple suggestion that the transverse reinforcement encloses the concrete in a rectangular section by arching effects. From Figure-9(a), it is evident that only the concrete enclosed by the four second-degree parabolas is sufficiently restrained while the remaining concrete has negligible confinement. Though there are discrepancies among steel and FRP in confining concrete, it has been observed that only part of the section is adequately confined. This has also been confirmed for FRP confinement (Lam and Teng, 2003b).

The adequacy of the confinement provided by FRP in square or rectangular concrete columns depends on the radius of the rounded corners. Al-Salloum (2007) reported that the behaviour of the FRP-confined square concrete columns gradually becomes similar to that of FRP-confined circular concrete columns with increasing corner radius, as illustrated in Figure-10. In Equation (2a), the diagonal length of the non-circular section of the concrete is substituted for the diameter of circular concrete section $\mathrm{d}$. However, for a non-circular concrete section with rounded corner radius $R_{c}$, the diagonal length of the section ' $d$ ' is given by:

$$
d=\sqrt{2 b}-2 R_{c}(\sqrt{2}-1)
$$




\section{THEORETICAL MODELS FOR CIRCULAR AND NON-CIRCULAR CONCRETE COLUMNS CONFINED BY FRP COMPOSITES}

Researchers have developed numerous confinement models to predict the compressive strength and ultimate strain of circular, rectangular, and square concrete columns confined by FRP reinforcement. While most of these models were developed on axially loaded FRP-confined unreinforced concrete columns, a limited number of models was developed on RC columns confined by FRP composites. The majority of these models are empirical and can be classified into two categories (Lam and Teng, 2003a): design-oriented models, in which closed-form equations obtained through regression analysis of the experimental results are used to predict the compressive strength, the ultimate strain, and stress-strain response of the strengthened concrete column (Lam and Teng, 2003a; Toutanji, 1999; Samaan et al., 1998), and analysis-oriented models, in which an incremental numerical method is employed to generate the stress-strain response of the concrete columns confined by FRP reinforcement (Spoelstra and Monti, 1999). Figure-11 illustrates a typical stress-strain model for concrete confined by FRP reinforcement (Lam and Teng, 2003a; Lam and Teng, 2003b). Most of these models assume the idea of Richart et al. (1928) and Mander et al. (1988) of defining the behaviour of concrete confined by FRP composites.

In Richart et al.'s (1928) model, the confinement strength and ultimate strain of concrete confined by hydrostatic fluid pressure are given by:

$$
\begin{aligned}
& f_{c c}^{\prime}=f_{c o}^{\prime}+k_{1} \cdot f_{l} . \\
& \varepsilon_{c c}=\varepsilon_{c o}\left(1+k_{2} \frac{f_{l}}{f_{c o}^{\prime}}\right)
\end{aligned}
$$

where $f_{c c}^{\prime}$ and $f_{c o}^{\prime}$ are confined and unconfined concrete compressive strength; $f_{l}$ is the lateral confining pressure; $\varepsilon_{c c}$ and $\varepsilon_{c o}$ are the strains of confined and unconfined concrete; $k_{1}$ and $k_{2}$ are the confinement effectiveness coefficients; and $k_{1}$ is taken as 4.1 and $k_{2}=5 k_{1}$.

Mander et al.'s (1988) model used a combined stress-strain procedure to define the compressive behaviour of circular and non-circular RC columns confined by transverse steel reinforcement. Figure-12 illustrates the stress-strain model, which is based on the axial compression test of concrete with slow (quasi-static) strain rate and monotonic loading. The compressive strength $f_{c c}^{\prime}$ and ultimate axial strain $\varepsilon_{c c}$ of the strengthened concrete are given as:

$$
\begin{aligned}
& f_{c c}^{\prime}=f_{c o}^{\prime}\left(-1.254+2.254 \sqrt{1+\frac{7.94 f_{l}^{\prime}}{f_{c o}^{\prime}}}-2 \frac{f_{l}^{\prime}}{f_{c o}^{\prime}}\right) \\
& \varepsilon_{c c}=\varepsilon_{c o}\left[1+5\left(\frac{f_{c c}^{\prime}}{f_{c o}^{\prime}}-1\right)\right]
\end{aligned}
$$

The compressive strain of the unconfined concrete $\varepsilon_{c o}$ usually assumes a value of 0.002 . 
The following section summarises a review of some of the existing theoretical models for circular and non-circular concrete confined by FRP reinforcement.

\subsection{Confinement Models for Axially Loaded FRP-Confined Circular Concrete Columns.}

\subsubsection{Saadatmanesh et al. (1994)}

Saadatmanesh et al. (1994) conducted an analytical investigation to examine the strength and ductility of circular RC columns wrapped with FRP composite straps. They adopted Mander et al. (1988) model for steel confined concrete to develop the analytical equations for the compressive strength and ultimate axial strain of CFRP and GFRP-confined concrete in circular and rectangular section. In Mander et al. (1988) model, the effective lateral confining pressure $f_{l}^{\prime}$ provided by the transverse reinforcement is uniform over the surface of the concrete core, and it is given by:

$$
f_{l}^{\prime}=f_{l} k_{e}
$$

where $f_{l}$ is the lateral confining pressure from transverse steel reinforcement and $k_{e}$ is the confinement effectiveness coefficient given by:

$$
k_{e}=\frac{A_{e}}{A_{c c}}
$$

where $A_{c c}$ is the effective area of concrete enclosed by FRP strap and $A_{e}$ is the area of effectively confined concrete core:

$$
\begin{aligned}
& A_{c c}=A_{c}\left(1-\rho_{c c}\right) \\
& \mathrm{A}_{\mathrm{e}}=\frac{\pi \mathrm{d}_{\mathrm{s}}{ }^{2}}{4}\left(1-\frac{\mathrm{s}^{\prime}}{2 \mathrm{~d}_{\mathrm{s}}}\right)^{2}
\end{aligned}
$$

Being $A_{c}$ the area of concrete confined by the FRP strap, $s^{\prime}$ the perpendicular distance between FRP straps, $\rho_{c c}$ the ratio of area of longitudinal reinforcement to gross area of concrete, and $d_{s}$ the diameter of column. Therefore, the confinement effectiveness coefficient $k_{e}$ becomes:

$$
k_{e}=\frac{\left(1-\frac{s^{\prime}}{2 d_{s}}\right)^{2}}{1-\rho_{c c}}
$$

However, for FRP confinement, the lateral confining pressure is given by:

$$
f_{l}=\frac{2 f_{f u} A_{s t}}{d_{s} s}
$$

where $A_{s t}$ is the cross-sectional area of FRP strip, $d_{s}$ is the diameter of column, $f_{f u}$ is the ultimate strength of FRP strap, and $s$ is the width of FRP strap. The volumetric ratio $\rho_{s}$ of confining FRP to concrete core is given by:

$$
\rho_{s}=\frac{A_{s t} \pi d_{s}}{\frac{\pi}{4} d_{s}^{2} s}=\frac{4 A_{s t}}{d_{S} s}
$$


Therefore, $f_{1}$ becomes:

$$
f_{l}=\frac{1}{2} \rho_{s} f_{f u}
$$

Saadatmanesh et al. (1994) proposed the following equations to predict the compressive strength and ultimate axial strain of FRP-confine concrete confined by changing the effective lateral confining pressure $f_{l}$ in Mander et al. (1988) equation with the lateral confining pressure of FRP strip placed in the circumferential tension:

$$
\begin{aligned}
& \frac{f_{c c}^{\prime}}{f_{c o}^{\prime}}=2.254 \sqrt{1+7.94 \frac{f_{l}}{f_{c o}^{\prime}}}-2 \frac{f_{l}}{f_{c o}^{\prime}}-1.254 \\
& \frac{\varepsilon_{c c}}{\varepsilon_{c o}}=1+5\left[\frac{f_{c c}^{\prime}}{f_{c o}^{\prime}}-1\right]
\end{aligned}
$$

\subsubsection{Mirmiran and Shahawy (1997)}

This model was developed based on experimental results of 30 axially loaded cylindrical concrete columns, which include 24 concrete filled E-glass FRP tubes and 6 plain concrete cylinders. The authors reviewed and assessed previous models (Mander et al., 1988; Samaan et al., 1998) and then combined them with test results obtained from their experimental investigation. Based on a regression analysis carried out on the combined test data (Figure-13.), the following strength equation was proposed for the compressive strength of circular concrete columns confined by FRP reinforcement.

$$
\frac{f_{c c}^{\prime}}{f_{c o}^{\prime}}=1+4.269\left(\frac{f_{l}^{0.587}}{f_{c o}^{\prime}}\right)
$$

\subsubsection{Karbhari and Gao (1997)}

This model was developed based on an analytical study carried out on three data sets. The first data set consisted of test results from Howie and Karbhari (1995) in which the wet-layup method was used to wrap carbon fibre-weaved fabric onto the concrete surface. The second data set was extracted using a similar technique, but incorporating adequate layers of resin for the purpose of environmental shield and to serve as a protective cover against moisture. The third data set was obtained from an experimental investigation conducted by Nanni and Bradford (1995) in which glass-aramid performed shells and epoxy-impregnated braided aramid tape was used in fabricating the test specimens. The datasets consisted of 15 axially loaded circular concrete columns confined by FRP composites and measuring $152 \mathrm{~mm}$ in diameter and $305 \mathrm{~mm}$ in height. The authors assumed a bilinear response of the stress-strain curve, as shown in Figure 14.

An effort has been exerted to motivate the application of simple design equations, and two models were proposed for concrete confined by FRP composites. The first model was developed from a simple composite analysis, while the second model was obtained by revising the original equations 
developed by previous researchers (Cusson and Paultre, 1995) using the test data from Howie and Karbhari (1995), and Karbhari and Eckel II (1994).

The first equation assumes non-linear response of the strengthened concrete. From Figure-14, the stress at point ' $A$ ' can be determined using the equation below:

$$
\sigma_{A}=f_{c o}^{\prime}+4.1 f_{c o}^{\prime} v_{c} \frac{2 t}{d} \frac{E_{f r p}}{E_{c}}
$$

where $E_{c}$ and $v_{c}$ are concrete tangent modulus and Poisson's ratio, and $E_{f r p}$ is the FRP modulus in the hoop direction. After the non-linearity response, the FRP commences active confinement, and the inner concrete behaves like a thick material. The ultimate stress of FRP-confined concrete at failure is given by:

$$
f_{c c}^{\prime}=\sigma_{A}+f_{l}^{\prime \prime}
$$

where $f_{l}^{\prime \prime}$ is the stress increment due to the confining action of FRP, which is defined as a function of the effective confining pressure and stress level at which failure initiates in concrete.

$$
f_{l}^{\prime \prime}=\frac{2 f_{f r p} t}{d}-f_{c o}^{\prime} v_{c} \frac{2 t}{d} \frac{E_{f r p}}{E_{c}}
$$

Therefore, the ultimate stress at failure becomes:

$$
f_{c c}^{\prime}=f_{c o}^{\prime}+3.1 f_{c o}^{\prime} v_{c} \frac{2 t}{d} \frac{E_{f r p}}{E_{c}}+\frac{2 f_{f r p} t}{d}
$$

The proposed equation for the ultimate axial strain is given by;

$$
\varepsilon_{c c}=1-\frac{1.004\left(1-\frac{f_{c o}^{\prime}}{E_{e f f}}-4.1 f_{c o}^{\prime} v_{c} \frac{2 t E_{f r p}}{d E_{c} E_{e f f}}\right)}{\left(1-\varepsilon_{f r p}\right)^{2}}
$$

where $E_{\text {eff }}$ is the effective elastic modulus of the system, which can be obtained using the rule of mixture method.

In the second model, the empirical equations were developed by regressing the data set using the least absolute deviation method. The ultimate stress equation takes the form similar to Cusson and Paultre's (1995) model, nonetheless differs in the coefficients. The proposed equations for the compressive strength and ultimate axial strain are given by:

$$
\begin{aligned}
& \frac{f_{c c}^{\prime}}{f_{c o}^{\prime}}=1+2.1\left(\frac{f_{l}^{\prime}}{f_{c o}^{\prime}}\right) \\
& \varepsilon_{c c}^{\prime}=\varepsilon_{c o}+0.01\left(\frac{f_{l}^{\prime}}{f_{c o}^{\prime}}\right)
\end{aligned}
$$

\subsubsection{Samaan et al. (1998)}

In this model, a series of 30 cylindrical concrete columns measuring $152.5 \mathrm{~mm}$ in diameter and $305 \mathrm{~mm}$ in length were tested under uniaxial compression. The cylindrical columns were encased with 
GFRP tubes having a thickness of six, ten and fourteen plies. Based on the bi-linear response of the stress-strain curve of FRP-confined concrete cylinders, simple design equations were proposed to predict the compressive strength and ultimate axial strain of the columns. The rate at which the concrete dilates, and the hoop stiffness of FRP confinement were correlated, and an expression for the confinement effectiveness coefficient $k_{1}$ is obtained:

$$
k_{1}=6.0 f_{l}^{-0.7}
$$

Substituting $\mathrm{k}_{1}$ into Richart et al. (1928) equation, the stress-strain equation for FRP-confined concrete is given by:

$$
\begin{aligned}
& f_{c c}^{\prime}=f_{c o}^{\prime}+6.0 f_{l}^{-0.7} \\
& \varepsilon_{c c}=\frac{f_{c c}^{\prime}-f_{o}}{E_{2}}
\end{aligned}
$$

Being $E_{2}$ the second slope of the axial stress-strain curve and $f_{o}$ the reference plastic stress at intercept of the second slope with the stress axis.

\subsubsection{Saafi et al. (1999)}

Saafi et al. (1999) investigated the behaviour of uniaxially loaded short concrete columns confined by FRP tubes. The test specimens consisted of 18 FRP-confined concrete cylinders and 12 plain circular concrete columns without FRP jacketing. The tested columns had a diameter of $152.4 \mathrm{~mm}$ and a height of $432 \mathrm{~mm}$. All the concrete cylinders had compressive strength of $38 \mathrm{MPa}$ and modulus of elasticity of 30GPa. The selected FRP tubes were prepared from CFRP (i.e. thickness of 0.8, 1.6 and 2.4mm) and GFRP (i.e. thickness of $0.11,0.23$ and $0.55 \mathrm{~mm}$ ). Based on experimental results, Saafi et al. (1999) reported that CFRP and GFRP-confined concrete cylinders demonstrated a significant increase in strength, ductility, and energy absorption. The failure of concrete cylinders confined with FRP tubes was rupture of the FRP tubes, which commence with a cracking noise during the early and middle stage of loading. They also confirmed that the confinement coefficient $k_{1}$ is a function of confining pressure and can be quantified by regressing the test results:

$$
k_{1}=2.2\left(\frac{f_{l}}{f_{c o}^{\prime}}\right)^{-0.16}
$$

Substituting $k_{l}$ into Richart et al. (1928) equation, the expression for the compressive strength given by:

$$
\frac{f_{c c}^{\prime}}{f_{c o}^{\prime}}=1+2.2\left(\frac{f_{l}}{f_{c o}^{\prime}}\right)^{0.84}
$$

The regression analysis of the test results also yield equation for the effectiveness coefficient $k_{2}$ :

$$
k_{2}=537 \varepsilon_{f}+2.6
$$


Based on Mander et al. (1988) equation, the ultimate axial strain is given by:

$$
\frac{\varepsilon_{\mathrm{cu}}}{\varepsilon_{\mathrm{co}}}=1+\left(537 \varepsilon_{\mathrm{f}}+2.6\right)\left(\frac{\mathrm{f}_{\mathrm{cc}}^{\prime}}{\mathrm{f}_{\mathrm{co}}^{\prime}}-1\right)
$$

\subsubsection{Toutanji (1999)}

Toutanji (1999) tested 18 plain concrete cylindrical specimens, in which, 12 were wrapped with CFRP and GFRP sheets and subjected to uniaxial loading. All the cylindrical concrete columns are measuring $76 \mathrm{~mm}$ in diameter and $305 \mathrm{~mm}$ in height. The results show that FRP wrapping can improve the strength and ductility of the concrete columns to about $200 \%$ as well as enhancing energy absorption. The author proposed an analytical model to predict the entire stress-strain relationship for FRP-confined concrete specimens by revising the model developed by Richart et al. (1928). Regression analysis carried out on the test results yield a confinement effectiveness coefficient $k_{l}$ :

$$
k_{1}=3.5\left(\frac{f_{l}}{f_{c o}^{\prime}}\right)^{-0.15}
$$

Substituting $k_{l}$ in Richart et al.'s (1928) equation, the axial compressive strength of the FRP-confined concrete is given by:

$$
\frac{f_{c c}^{\prime}}{f_{c o}^{\prime}}=1+3.5\left(\frac{f_{l}}{f_{c o}^{\prime}}\right)^{0.85}
$$

Similarly, the author proposed equation for the ultimate axial strain of FRP-confined concrete columns by introducing a strain coefficient $k_{2}$ in Mander et al.'s (1988) equation. The value of $k_{2}$ is obtained by regressing the test results:

$$
k_{2}=310.57 \varepsilon_{l}+1.90
$$

where $\varepsilon_{l}$ is the lateral strain of strengthened column. Therefore, the ultimate axial strain becomes:

$$
\frac{\varepsilon_{c c}}{\varepsilon_{c o}}=1+\left(310.57 \varepsilon_{1}+1.90\right)\left(\frac{f_{l}}{f_{c o}^{\prime}}-1\right)
$$

\subsubsection{Lam and Teng (2002)}

This model was developed from a statistical analysis carried out on an extensive database comprising of over 200 tests results from a comprehensive review of existing studies on circular unreinforced concrete columns confined by FRP. Based on analysis of the test results, the authors found that a direct correlation exist between the confined concrete strength and lateral confining pressure produced by externally bonded FRP. Statistical analysis was carried out on the test data, and the following equation was proposed to predict the compressive strength of FRP-confined concrete;

$$
\frac{f_{c c}^{\prime}}{f_{c o}^{\prime}}=1+2 \frac{f_{l}}{f_{c o}}
$$




\subsubsection{Lam and Teng (2003a)}

This model is a design-oriented stress-strain model for FRP-confined concrete developed from analysis of an extensive test database from 76 circular concrete columns confined by FRP composites. The analysis results of the test database show that all the specimens exhibited the mechanism of FRP rupture due to hoop tension. The results of the analysis also indicate that externally bonded FRP composites ruptured before achieving its material tensile strength. Accordingly, the actual confining pressure $f_{l a}$ was used in developing the model rather than the normal confining pressure value $f_{l}$. The ultimate compressive strength and ultimate strain of FRP-confined concrete are given by:

$$
\begin{aligned}
& \frac{f_{c c}^{\prime}}{f_{c o}^{\prime}}=1+3.3 \frac{f_{l, a}}{f_{c o}^{\prime}} \\
& \frac{\varepsilon_{c u}}{\varepsilon_{c o}}=1.75+12\left(\frac{f_{l, a}}{f_{c o}^{\prime}}\right)\left(\frac{\varepsilon_{h, r u p}}{\varepsilon_{c o}}\right)^{0.45} \\
& f_{l, a}=\frac{2 E_{f r p} t \varepsilon_{h, r u p}}{d}
\end{aligned}
$$

Being $f_{l a}$ the actual confining pressure, $E_{f r p}$ the elastic modulus of FRP material, and $\varepsilon_{h, r u p}$ the FRP hoop strain at rupture.

However, the authors proposed an efficiency factor $\left(\frac{\varepsilon_{h, f r p}}{\varepsilon_{f r p}}\right)$ of 0.586 for CFRP composites. Therefore, the ultimate strain of CFRP-confined concrete becomes;

$$
\frac{\varepsilon_{c u}}{\varepsilon_{c o}}=1.75+5.53\left(\frac{f_{l, a}}{f_{c o}^{\prime}}\right)\left(\frac{\varepsilon_{f r p}}{\varepsilon_{c o}}\right)^{0.45}
$$

\subsubsection{Xiao and $W u(2003)$}

Xiao and $\mathrm{Wu}$ (2003) tested 243 standard circular concrete columns wrapped with CFRP and GFRP jackets, and measuring $152 \mathrm{~mm}$ in diameter and $300 \mathrm{~mm}$ in height under uniaxial compressive loading. The results obtained from compressive testing of concrete cylinders wrapped with CFRP jacket was used in developing the model. The results of the work show that initial part of the stressstrain curve (Figure-15.) for CFRP-confined concrete resembled that of unconfined concrete before reaching maximum stress. After exceeding maximum stress, the stress-strain curves of the strengthened columns showed a linear behaviour until rupture of the CFRP. Considering the linear elastic behaviour of CFRP jackets, a constant confinement modulus $C_{f}$ was introduced, which was defined as a function of FRP jacket thickness $t_{f}$, column diameter $D$ and FRP jacket modulus $E_{f}$ :

$$
C_{f}=\frac{2 t_{f}}{D} E_{f}
$$

The linear portion of the axial and confinement stress relationship is given by:

$$
\frac{f_{c c}^{\prime}}{f_{c o}^{\prime}}=\alpha+k \frac{f_{l}}{f_{c o}^{\prime}}
$$


where $\alpha$ and $k$ are the intersections with vertical and slope of linear portion of the stress-strain curve, respectively. The value of $\alpha$ was averagely taken as 1.1 for all the specimens and $k$ was obtained from regression analysis of the test results:

$$
k=4.1-0.45\left[\frac{f_{c o}^{\prime 2}}{C_{f}}\right]^{1.4}
$$

Therefore, the axial stress and confinement stress relationship becomes:

$$
\frac{f_{c c}^{\prime}}{f_{c o}^{\prime}}=1.1+\left[4.1-0.45\left(\frac{f_{c o}^{\prime 2}}{c_{f}}\right)^{1.4}\right] \cdot \frac{f_{l}}{f_{c o}^{\prime}}
$$

However, a linear relationship was proposed for the axial transverse strain response of linear portion of the curve:

$$
\varepsilon_{f u}=\varepsilon_{r 0}^{\prime}-v^{\prime} \varepsilon_{c c}
$$

where $\varepsilon_{r 0}^{\prime}$ is the intersection of linear line at zero axial strain and had an average value of -0.00047 , and $v^{\prime}$ is the slope of the line, which increases for higher concrete strength $f_{c o}^{\prime}$ and lower confinement modulus $C_{f}$ and is given by:

$$
v^{\prime}=10\left(\frac{f_{c o}^{\prime}}{C_{f}}\right)^{0.9}
$$

Therefore, the axial-transverse strain relationship becomes:

$$
\varepsilon_{c c}=\frac{\varepsilon_{f u}-0.00047}{10\left[f_{c o}^{\prime} / C_{f}\right]^{0.9}}
$$

\subsubsection{Matthys et al. (2006)}

This model was developed based on experimental investigation of six axially loaded largescale FRP-wrapped circular concrete columns. The authors observed a strong relationship between the ultimate strength of FRP-confined concrete and the strain of FRP jackets at failure. The circumferential strain at failure was less than the ultimate strain obtained from the standard FRP coupons tensile testing. Based on these observations, previous model developed by Toutanji (1999) was revised by introducing an effective FRP strain coefficient $\beta(\beta=0.6)$, which accounts for the decrease in lateral confining stress. Therefore, the ultimate lateral confining pressure is given by:

$$
\begin{aligned}
& f_{l}=\frac{2 t_{f} E_{f} \varepsilon_{c l u}}{D} \\
& \varepsilon_{c l u}=\beta \varepsilon_{f u}
\end{aligned}
$$

where $\varepsilon_{f u}$ is the ultimate strain of FRP, and $\varepsilon_{c l u}$ is the ultimate circumferential failure strain of FRP. The revised Toutanji (1999) equation for the ultimate compressive strength of FRP-confined concrete is given by: 


$$
\frac{f_{c c}^{\prime}}{f_{c o}^{\prime}}=1+2.3\left(\frac{f_{l}}{f_{c o}^{\prime}}\right)^{0.85}
$$

\subsubsection{Cui and Sheikh (2010a)}

Cui and Sheikh (2010a) proposed an iterative, incremental procedure to predict the compressive stress-strain behaviour of normal and high strength concrete confined with FRP composites. The constitutive model was developed based on the compressive behaviour of concrete, the tensile properties of FRP as well as the interaction between concrete and FRP using four quadrants of relationships (Figure-16). The stress-strain model developed by Attard and Setunge (1996) for confined concrete was used to generate the models due to its wide range of applicability. Cui and Sheikh (2010a) reported that the expressions developed by Attard and Setunge (1996) for peak stress and strain of confined concrete failed to give accurate predictions of the test results. Consequently, the authors proposed the following analytical expressions for the peak stress and strain of normal and high strength concrete confined with FRP using test results from Laine (2004).

$$
\begin{aligned}
& \frac{f_{c c}^{\prime}}{f_{c o}^{\prime}}=\left(1+10 \frac{f_{c o n}}{f_{c o}^{\prime}}\right)^{0.6} \quad \text { for } \quad f_{c o}^{\prime}<60 \mathrm{MPa} \\
& \frac{f_{c c}^{\prime}}{f_{c o}^{\prime}}=\left(1+14 \frac{f_{c o n}}{f_{c o}^{\prime}}\right)^{0.5} \quad \text { for } \quad f_{c o}^{\prime} \geq 60 \mathrm{MPa} \\
& \frac{\varepsilon_{c c}^{\prime}}{\varepsilon_{c o}^{\prime}}=1+\left[70-13 \ln \left(f_{c o}^{\prime}\right)\right] \cdot\left(\frac{f_{c o n}}{f_{c o}^{\prime}}\right)
\end{aligned}
$$

where $f_{\text {con }}$ is the confining stress given by:

$$
f_{\text {con }}=\frac{2 n_{f r p} f_{f}}{D}=\frac{2 n_{f r p} E_{f r p} \varepsilon_{f r p}}{D}
$$

Being $E_{f r p}$ the elastic modulus of FRP, $f_{f}$ and $\varepsilon_{f r p}$ the tensile stress and tensile strain of FRP, and $n_{f r p}$ the number of FRP layers.

However, Cui and Sheikh (2010a) modelled the dilation of confined concrete regarding the volumetric strain $\varepsilon_{v}$ by revising the equations developed by (1mran and Pantazopoulou, 1996) based on the test data from Laine (2004).

$$
\varepsilon_{v}=\left(1-2 v_{o}\right)\left[\frac{2 f_{c o n}}{E_{c}}+\varepsilon_{c}^{v o}\left(\frac{\varepsilon_{c}}{\varepsilon_{c}^{v o}}-b\left[\frac{\left\langle\varepsilon_{c}-\varepsilon_{c}^{l i m}\right\rangle}{\varepsilon_{c}^{v o}-\varepsilon_{c}^{l i m}}\right]^{c}\right)\right]
$$

where $\varepsilon_{v}$ is the volumetric strain of concrete given by;

$$
\varepsilon_{v}=\varepsilon_{c}+2 \varepsilon_{\text {con }}
$$

The lateral cracking strain of concrete $\varepsilon_{c}^{\text {lim }}$ is given by:

$$
\varepsilon_{c}^{l i m}=\frac{1-v_{o}}{v_{o} E_{c}} \cdot f_{\text {con }}-\frac{\varepsilon_{c r}}{v_{o}}
$$

where $v_{o}$ is the Poisson's ratio of concrete and $\varepsilon_{\mathrm{cr}}$ is the strain corresponding to the concrete splitting at stress $f_{c r}$ and is given by (Arıglu et al. 2006):

$$
\varepsilon_{c r}=\frac{f_{c r}}{E_{c}}=0.387 \frac{\left(f_{c o}^{\prime}\right)^{0.63}}{E_{c}}
$$


The axial strain at zero volumetric strain is taken as $\varepsilon_{c}^{v o}=a \varepsilon_{c c}^{\prime}$, and the McCauley brackets \langle\rangle are defined as $\langle x\rangle=0.5[x+a b s(x)]$. The factors $b$ and $c$ are parameters accounting for the effect of confinement ratio on the curve shape, which are given by:

$$
\begin{aligned}
& 0.65 \leq a=\frac{f_{c o}^{\prime}}{\left\langle f_{c o}^{\prime}-50\right\rangle+40}-0.1 \leq 1.1 \\
& b=1-\frac{f_{c o n}}{f_{c o}^{\prime}} \geq 0.7 \\
& c=\frac{f_{c o}^{\prime}-f_{c o n}}{30} \geq 2.0
\end{aligned}
$$

\subsubsection{Chastre and Silva (2010)}

Chastre and Silva (2010) investigated the behaviour of circular RC columns confined with CFRP composites under monotonic axial loading. The authors proposed a constitutive stress-strain model for CFRP-confined circular column under compressive loading. The proposed model adapted the Richart et al.'s (1928) model and considers the combined lateral confinement provided by FRP and steel hoops. The compressive strength of FRP confined concrete is given by:

$$
f_{c c}=f_{D}+5.29 f_{l u}
$$

where $f_{l u}$ is the lateral confining pressure, and $f_{D}$ is the compressive strength of concrete given by:

$$
\begin{aligned}
& f_{D}=\alpha f_{C o} \\
& \alpha=\left(\frac{1.5+\frac{D}{H}}{2}\right)
\end{aligned}
$$

where $D$ and $H$ are diameter and height of the column. The combined lateral confining pressure $f_{l u}$ is given by:

$$
\begin{aligned}
& f_{l u}=f_{j u}+f_{s h u} \\
& f_{j u}=\frac{2 t}{D} E_{f} \varepsilon_{l u} \\
& f_{s h u}=\frac{2 A_{s w}}{d_{w} s} f_{s w}
\end{aligned}
$$

Being $t$ and $E_{f}$ the thickness and Young's modulus of FRP jacket, $\varepsilon_{l u}$ the lateral rupture strain of FRP jacket, $A_{s w}$ and $d_{w}$ the cross-sectional area and diameter of steel hoops, and $s$ the spacing between steel hoops. The tensile strength of steel hoops is given by:

$$
f_{s w}= \begin{cases}E_{s} \times \frac{d_{w}}{D} \varepsilon_{l u} & \text { for } \varepsilon_{l u}<\frac{D}{d_{w}} \varepsilon_{l u} \\ f_{y} & \text { for } \varepsilon_{l u} \geq \frac{D}{d_{w}} \varepsilon_{l u}\end{cases}
$$


It was revealed that the lateral failure strain $\varepsilon_{l u}$ of CFRP jacket is less than the rupture strain $\varepsilon_{f u}$ as confirmed by previous studies (Lam and Teng, 2004; Matthys, 2000; Samaan et al., 1998). Therefore, the lateral failure strain of CFRP is given by:

$$
\varepsilon_{l u}=0.6 \varepsilon_{f u}
$$

Chastre and Silva (2010) proposed the following equation to predict the peak axial strain of FRP confined circular concrete columns under compressive load:

$$
\varepsilon_{c c}=17.65 \varepsilon_{c o}\left(\frac{f_{l u}}{f_{D}}\right)^{0.7}
$$

where $\varepsilon_{c o}$ is given by (BS EN 1992-1-1 2004):

$$
\varepsilon_{c o}=\frac{0.7}{1000}\left(f_{c o}\right)^{0.31}
$$

\subsubsection{Ozbakkaloglu and Lim (2013)}

In this model, an extensive database of test results from 832 FRP-confined circular concrete column subjected to axial loading was analysed. Based on statistical analysis of the test data, a hoop strain reduction factor $k_{\varepsilon f}$ was introduced to account for the decrease in the hoop rupture strain of FRP composite resulting from increased in either compressive strength of concrete or elastic modulus of FRP jackets. This reduction factor is given by:

$$
k_{\varepsilon f}=0.9-2.3 f_{c o}^{\prime} \times 10^{-3}-0.75 E_{f} \times 10^{-6}
$$

However, the authors reported that Equation (18a) can predict the FRP strain reduction factor with a concrete strength up to $120 \mathrm{MPa}$, and confined by any FRP types (CFRP, AFRP and GFRP). The proposed equation for the compressive strength of FRP-confined concrete is given by:

$$
\begin{aligned}
& f_{c c}^{\prime}=\left(1+0.0058 \frac{k_{1}}{f_{c o}^{\prime}}\right) f_{c o}^{\prime}+k_{1}\left(f_{\text {lua }}-f_{l o}\right) \\
& k_{1}=\frac{2 E_{f} t_{f}}{D} \\
& f_{l o}=k_{1}\left(0.43+0.009 \frac{k_{1}}{f_{c o}^{\prime}}\right) \varepsilon_{c o}
\end{aligned}
$$

where $k_{l}$ is the axial strength enhancement coefficient $\left(k_{1} \geq f_{c o}^{\prime 1.65}\right)$, and $f_{l o}$ is the threshold confining pressure.

The proposed equation for the ultimate axial strain $\left(\varepsilon_{c u}\right)$ of FRP-confined concrete is expressed as a non-linear function of confinement stiffness $\left(k_{1}\right)$, hoop rupture strain $\left(\varepsilon_{h, \text { rup }}\right)$ and unconfined concrete strength $\left(f_{c o}^{\prime}\right)$ using the equation developed by previous researchers (Tasdemir et al., 1998).

$$
\varepsilon_{c u}=c_{2} \varepsilon_{c o}+0.27\left(\frac{k_{1}}{f_{c o}^{\prime}}\right) \varepsilon_{h, r u p}^{1.35}
$$


The normalised ultimate coefficient $c_{2}$ is statistically evaluated:

$$
c_{2}=2-\left(\frac{f_{c o}^{\prime}-20}{100}\right), \quad \text { and } \quad c_{2} \geq 1
$$

\subsubsection{Wu and Wei (2014)}

The model of $\mathrm{Wu}$ and Wei (2014) was developed based on analytical study and data regression of large database from 706 test results having concrete strength range of $6.2-111.8 \mathrm{MPa}$. Through careful regression analysis using the tests data, the authors proposed the following stress-strain equations to predict the compressive strength and ultimate axial strain of FRP-confined concrete.

$$
\begin{aligned}
& \frac{f_{c u}}{f_{c o}}=0.75+2.7\left(\frac{f_{l}}{f_{c o}}\right)^{0.9} \\
& \frac{\varepsilon_{c u}}{\varepsilon_{c o}}=1.75+140\left(\frac{f_{l}}{f_{c o}}\right) \varepsilon_{f u}^{0.6}
\end{aligned}
$$

where $\varepsilon_{f u}$ is the FRP rupture strain.

\subsection{Confinement Models for Axially Loaded FRP-Confined Non-Circular Concrete Columns}

\subsubsection{Lam and Teng (2003b)}

This model is an extension of the design-oriented stress-strain model developed by the same researchers (Lam and Teng, 2003a) for axially loaded circular concrete columns confined by FRP composites. A database from existing test results and experimental results obtained by the authors were used in developing the equations. In this model, two shape factors were introduced due to the increase in the section aspect ratio which has led to the decrease in the compressive strength and increase in the ultimate axial strain. These shape factors are strength enhancement factor $k_{s} l$ and strain enhancement factor $k_{s 2}$. The proposed expressions for the compressive strength and ultimate axial strain are given by:

$$
\begin{aligned}
& \frac{f_{c c}^{\prime}}{f_{c o}^{\prime}}=1+k_{1} k_{s 1} \frac{f_{l}}{f_{c o}^{\prime}} \\
& \frac{\varepsilon_{c u}}{\varepsilon_{c o}}=1.75+k_{2} k_{s 2} \frac{f_{l}}{f_{c o}^{\prime}}\left(\frac{\varepsilon_{h, r u p}}{\varepsilon_{c o}}\right)^{0.45} \\
& k_{s 1}=\left(\frac{b}{h}\right)^{2} \frac{A_{e}}{A_{c}} \\
& k_{s 2}=\left(\frac{h}{b}\right)^{0.5} \frac{A_{e}}{A_{c}}
\end{aligned}
$$

where, $b$ and $h$ are the shorter and longer sides of the rectangular section, $A_{c}$ is the total area of concrete, $A_{e}$ is the area of efficiently confined concrete, $k_{l}$ and $k_{2}$ are the constant values obtained from regression analysis and were taken as 3.3 and 12 as defined in the previous study (Lam and Teng, 
2003a) for uniformly confined concrete. The term $\frac{A_{e}}{A_{c}}$ is the effective confinement area ratio defined as:

$$
\begin{aligned}
& \frac{A_{e}}{A_{c}}=\frac{1-\left((b / h)\left(h-2 R_{c}\right)^{2}+(h / b)\left(b-2 R_{c}\right)^{2} /\left(3 A_{g}\right)\right)-\rho_{s c}}{1-\rho_{s c}} \\
& A_{g}=b h-(4-\pi) R_{c}^{2}
\end{aligned}
$$

where $A_{g}$ is the gross section area of the column with rounded corners, and $\rho_{s c}$ is the cross-sectional area ratio of longitudinal steel reinforcement.

\subsubsection{Shehata et al. (2001)}

Shehata et al. (2001) tested 54 plain concrete short columns wrapped with CFRP reinforcements under axial compression. The parameters of the study were the type of cross-section (i.e. circular, square and rectangular) and amount of FRP sheets (one and two layers). The specimens were grouped into three, with each group having 18 specimens according to the cross-section shape. All the three groups were subdivided into three subgroups with six samples in each subgroup according to the degree of FRP confinement (i.e. unconfined and confined with one or two layers of the FRP). All the concrete columns have an unconfined concrete strength of around $25-30 \mathrm{MPa}$. The circular concrete columns are measuring $150 \mathrm{~mm}$ in diameter, the square concrete columns had a crosssection of $150 \mathrm{~mm} \times 150 \mathrm{~mm}$, and the rectangular specimens had a cross-section of $94 \mathrm{~mm} \times 188 \mathrm{~mm}$. All the specimens maintained the same height of $300 \mathrm{~mm}$ and sharp corners of the square and rectangular specimens were rounded with a corner radius of $10 \mathrm{~mm}$. The results indicate that the efficiency of FRP confinement was sensitive to the geometry of cross-section and the degree of confinement. The authors also reported that the coefficient $k_{1}$ depends on level of FRP confinement and concrete strength. Based on these observations, the researchers proposed design equations for FRP-confined concrete in circular, square and rectangular cross-sections. The proposed equations were developed through regression analysis using the test results.

\section{a. Circular cross-section}

The compressive strength of FRP confined concrete is calculated using the following equations:

$$
\begin{gathered}
\frac{f_{c c}}{f_{c o}}=1+2.0 \frac{f_{l}}{f_{c o}} \\
f_{l}=\frac{2 f_{f r p} t_{f r p}}{D}
\end{gathered}
$$

where $D$ is the diameter of confined concrete. However, the ultimate axial strain of FRP-confined concrete is given by:

$$
\frac{\varepsilon_{c c}}{\varepsilon_{c o}}=1+632\left(\frac{f_{l}}{f_{c o}} \cdot \frac{f_{c c}}{E_{f r p}}\right)^{0.5}
$$




\section{a. Square cross-section}

The average compressive strength of FRP-confined concrete of square cross-section is given by:

$$
\frac{f_{c c}}{f_{c o}}=1+0.85 \frac{f_{l}}{f_{c o}}
$$

Moreover, the average ultimate axial strain is calculated as:

$$
\frac{\varepsilon_{c c}}{\varepsilon_{c o}}=1+13.5 \frac{f_{l}}{f_{c o}}
$$

\section{b. Rectangular cross-section}

The average compressive strength of FRP-confined concrete of rectangular column cross-section is calculated as follows:

$$
\frac{f_{c c}}{f_{c o}}=1+0.7 \frac{f_{l}}{f_{c o}}
$$

Moreover, the ultimate strain is given by:

$$
\frac{\varepsilon_{c c}}{\varepsilon_{c o}}=1+12.4 \frac{f_{l}}{f_{c o}}
$$

\subsubsection{Kumutha et al. (2007)}

Kumutha et al. (2007) performed an experimental study on behaviour of 9 rectangular RC columns confined with GFRP wraps under axial compressive loading. The parameters investigated include aspect ratio of the cross-section (i.e. $a / b=1, a / b=1.25$, and $a / b=1.66$ ) and number of GFRP layers (i.e. zero, one, and two layers). The specimens had a cross-sectional area of $15625 \mathrm{~mm}^{2}$ and a height of $750 \mathrm{~mm}$, with a concrete compressive strength of approximately $27.45 \mathrm{MPa}$. The failure pattern of GFRP-confined concrete columns was concrete crushing at or near the column ends followed by rupture of FRP in the circumferential direction. Because of high-stress concentration at sharp edges, the failure initiates at or near the edges of columns. The authors concluded that strength gain in all the GFRP-confined columns is directly related to aspect ratio of the cross-section because it decreases with increase in aspect ratio. The authors proposed a simple analytical strength model by analyzing the experimental results. The model adapted Richart et al.'s (1928) model, nevertheless differs in the lateral confining pressure $f_{l}$. The authors suggested that the effective confining pressure should replace the lateral confining pressure, because FRP confinement in rectangular concrete crosssection is non-uniform. The effective confining pressure is given by:

$$
f_{l}^{\prime}=k_{s} f_{l}
$$

where $k_{s}$ is a shape factor accounting for the influence of column cross-section. The revised Richart et al.'s (1928) model becomes:

$$
f_{c c}^{\prime}=f_{c o}^{\prime}+k_{1} k_{s} f_{l}
$$

The term $k_{1} k_{s}$ is obtained by regression analysis of experimental test results and it was found to be 0.93. The proposed equation for the compressive strength of FRP confined concrete is given by: 


$$
\frac{f_{c c}^{\prime}}{f_{c o}^{\prime}}=1+0.93 \frac{f_{l}}{f_{c o}^{\prime}}
$$

The authors further commented that a good correlation exists between experimental and analytical results with a maximum error of $7 \%$. The model can be applied to RC square and rectangular columns confined with FRP.

\subsubsection{Wu et al. (2007)}

The model of Wu et al. (2007) is a design-oriented stress-strain model developed based on analytical investigation of a database containing more than 100 test results from previous studies. The database covered an extensive range of parameters that affect the mechanism of FRP confinement. The test results consisted of FRP-confined plain concrete columns of the square and rectangular crosssection and having concrete compressive strength range from 23.6 to $75.4 \mathrm{MPa}$. The columns had cross-section dimensions of the range between $100 \mathrm{~mm}$ and $500 \mathrm{~mm}$, and height range of $150 \mathrm{~mm}$ and $1500 \mathrm{~mm}$, respectively. The specimens had a corner radius ranges between $5 \mathrm{~mm}$ and $50 \mathrm{~mm}$, respectively. The selected specimens were those confined with CFRP, GFRP and AFRP composites in the form of FRP tube or FRP sheet. The FRP composites had a varying thickness between $0.11 \mathrm{~mm}$ and $8.0 \mathrm{~mm}$, with a tensile strength varied between 230 and 4433MPa. The FRP composites selected in the study also have varying modulus in the range of 13.6-640MPa. Analytical investigation of the database showed that the stress-strain behaviour of FRP-confined concrete prism exhibited either a strain-hardening or a strain softening response, which depends on the strength of FRP confinement, corner radius, concrete strength, and column cross-section. The authors also reported that transitional stress and strain of FRP-confined concrete prism are significantly affected by the ratio of confining FRP modulus to concrete modulus. Based on these observations, a factor $\lambda_{0}$ was introduced to predict the transitional stress and strain of FRP-confined concrete prisms:

$$
\lambda_{0}=\frac{E_{1}}{E_{c}}
$$

where $E_{c}$ is the elastic modulus of unconfined concrete and $E_{l}$ is the FRP lateral confinement stiffness given by:

$$
E_{1}=\frac{1}{2} \rho_{f} E_{f},
$$

where $E_{f}$ is the modulus of elasticity of FRP and $\rho_{\mathrm{f}}$ is the volumetric ratio of FRP to concrete, which can be calculated as follows:

- For fully wrapped concrete prisms

$$
\rho_{f}=\frac{2(b+h) t_{f}}{b h}
$$

- For partially wrapped concrete prisms 


$$
\rho_{f}=\frac{2(b+h) t_{f} b_{f}}{b h\left(b_{f}+s_{f}\right)}
$$

where $b_{f}$ is the width of FRP strips and $s_{f}$ is the net space of each FRP strip. For unification, $\lambda_{0}$ is modified to $\lambda_{1}$ :

$$
\lambda_{1}=\frac{\rho_{f} E_{f}}{\sqrt{f_{c o}^{\prime}}}
$$

where $f_{c o}^{\prime}$ is the uniaxial compressive strength of concrete cylinders. However, another factor $\alpha$ is introduced to account for the influence of unconfined concrete strength on transitional stress and strain of FRP-confined concrete, and it is given by:

$$
\alpha=\frac{30}{f_{c o}^{\prime}}
$$

The influence of modulus of elasticity of FRP on confinement effectiveness was also taken into consideration, and a coefficient $k_{1}$ was introduced to account for the gain in FRP confinement efficiency due to increased modulus of elasticity of FRP reinforcement.

$$
k_{1}= \begin{cases}1, & E_{f} \leq 250(G P a) \\ \sqrt{\frac{E_{f}}{250}}, & E_{f}>250(G P a)\end{cases}
$$

The regression equation for the transitional stress of FRP-confined concrete prism is given by:

$$
\frac{\sigma_{c p}}{f_{c o}}=1+0.0008 \alpha k_{1} \lambda_{1}
$$

Similarly, the transitional strain of FRP-confined concrete prisms was proposed by introducing a factor $k_{2}$ to account for the influence of FRP modulus on transitional strain of FRP-confined concrete prisms. The transitional strain was expressed as a function of FRP confinement stiffness, unconfined concrete strength and modulus of elasticity of FRP.

$$
k_{2}= \begin{cases}1, & E_{f} \leq 250(G P a) \\ \frac{250}{E_{f}}, & E_{f}>250(G P a)\end{cases}
$$

Based on regression analysis, the transitional strain of FRP confined concrete is given by:

$$
\frac{\varepsilon_{c p}}{\varepsilon_{c o}}=1+0.0034 \alpha k_{2} \lambda_{1}
$$

where $\varepsilon_{c o}$ is the peak strength of unconfined concrete, and was taken as 0.002 ;

Moreover, the ultimate strength and strain of FRP-confined concrete prism are approximated by reducing the ultimate strength, and ultimate axial strain of equivalent FRP-confined concrete cylinders with reduction factors $k_{3}$ for strength and $k_{4}$ for the strain. The expressions for the ultimate strength and ultimate axial strain for FRP-confined concrete prisms are given by: 


$$
\begin{aligned}
& \mathrm{f}_{\mathrm{cu}}=\mathrm{k}_{3} \mathrm{f}_{\mathrm{cu}}^{\prime} \\
& \varepsilon_{\mathrm{cu}}=\mathrm{k}_{4} \varepsilon_{\mathrm{cu}}^{\prime}
\end{aligned}
$$

where $f_{c u}^{\prime}$ and $\varepsilon_{c u}^{\prime}$ are the ultimate strength and ultimate axial strain of equivalent FRP-confined concrete cylinders having the same degree of confinement as proposed in the previous model (Wu et al., 2006). The proposed equations for predicting the compressive strength of equivalent FRP-confined concrete cylinders are as follows:

- For Common modulus FRP sheet

$$
\frac{f_{c u}^{\prime}}{f_{c o}^{\prime}}=1+2\left(\frac{f_{l}}{f_{c o}^{\prime}}\right), f_{l} / f_{c o}^{\prime} \geq \lambda
$$

- For FRP tube

$$
\frac{f_{c u}^{\prime}}{f_{c o}^{\prime}}=1+2.5\left(\frac{f_{l}}{f_{c o}^{\prime}}\right)
$$

- For high modulus CFRP

$$
\frac{f_{c u}^{\prime}}{f_{c o}^{\prime}}=1+2.4\left(\frac{f_{l}}{f_{c o}^{\prime}}\right)
$$

- For common modulus CFRP sheet

$$
\frac{f_{c u}^{\prime}}{f_{c o}^{\prime}}=0.75+2.5\left(\frac{f_{l}}{f_{c o}^{\prime}}\right), \quad f_{l} / f_{c o}^{\prime}<\lambda
$$

The strength reduction factor $k_{3}$ is evaluated through regression analysis of experimental data.

$$
k_{3}= \begin{cases}(2-\alpha) \frac{r}{h}+0.5 \alpha, & E_{f} \leq 250(G P a) \\ \left(2-\sqrt{\frac{E_{f}}{250}}\right) \frac{r}{h}+0.5 \sqrt{\frac{E_{f}}{250} \alpha} & E_{f}>250(G P a)\end{cases}
$$

The strain reduction factor $k_{4}$ and $\varepsilon_{c u}^{\prime}$ are calculated based on whether the stress-strain behaviour of the equivalent FRP-confined concrete cylinder is a strain-hardening or strain-softening response.

- For strain-hardening response;

$$
\begin{aligned}
& k_{4}=(2-1.6 \alpha) \frac{r}{h}+0.8 \alpha \\
& \varepsilon_{c u}^{\prime}=\frac{\varepsilon_{f u}}{v_{u}}, \quad \quad f_{l} / f_{c o}^{\prime} \geq \lambda
\end{aligned}
$$

- For strain-softening response;

Regression analysis of the experimental data yields the equations for $k_{4}$ as:

$$
k_{4}= \begin{cases}(2-1.6 \alpha) \frac{r}{h}+0.8 \alpha & E_{f} \leq 250(G P a) \\ \left(2-1.6 \sqrt{\left.\frac{E_{f}}{250} \alpha\right) \frac{r}{h}+0.8 \sqrt{\frac{E_{f}}{250} \alpha}}\right. & E_{f}>250(G P a)\end{cases}
$$




$$
\varepsilon_{c u}^{\prime}=\varepsilon_{c u}\left(1.3+6.3 \frac{f_{l}}{f_{c o}^{\prime}}\right), \quad f_{l} / f_{c o}^{\prime}<\lambda
$$

where $h$ is the height of rectangular cross-section, $r$ is the corner radius of the cross-section, and $\lambda$ is the boundary value of strain-hardening and strain-softening for the FRP-confined equivalent concrete cylinder.

\subsubsection{Al-Salloum (2007)}

Al-Salloum (2007) conducted an experimental and analytical investigation on the influence of corner radius of cross-section on the strength of small-scale FRP-confined square concrete columns subjected to axial compression. The specimens consisted of 16 unreinforced square concrete columns having a cross-section of $150 \mathrm{~mm} \times 150 \mathrm{~mm}$ and a height of $500 \mathrm{~mm}$. The column specimens were divided into four groups according to the size of corner radius (i.e. $5 \mathrm{~mm}, 25 \mathrm{~mm}, 38 \mathrm{~mm}$ and $50 \mathrm{~mm}$ ). Two specimens from each group were wrapped with one layer of CFRP jacket, while the remaining specimens were taken as control. Four plain concrete cylinders measuring $150 \mathrm{~mm}$ in diameter and $300 \mathrm{~mm}$ in height were also prepared, in which, two specimens were wrapped with one layer of CFRP sheet. Based on experimental results obtained, the author proposed a strength model to predict the compressive strength of FRP-confined concrete with circular or square cross-section by considering a shape factor $k_{e}$, which is expressed as a function of cross-section dimension $b$ and corner radius $r$ :

$$
k_{e}=1-\frac{2}{3}\left(\frac{\left(1-2 \frac{r}{b}\right)^{2}}{1-(4-\pi)\left(\frac{r}{b}\right)^{2}}\right)
$$

For circular concrete columns, the maximum value of $k_{e}$ is 1 when $r / b=1 / 2$. Furthermore, by considering the non-uniformity in the confinement effectiveness in square section, a modification factor $b / D$ was introduced to account for non-uniformity in the confining pressure. The modification factor $b / D$ assumes a maximum value of 1 for fully confined circular concrete section. The model adapted the general equation developed by Richart et al. (1928) for FRP-confined concrete, with $k_{1}=3.14$ obtained by taking the average of 3.3 and 2.8 as proposed in the previous model (Lam and Teng, 2003a). The general model for the compressive strength of FRP-confined concrete in both circular and square sections is given by:

$$
\begin{aligned}
& \frac{f_{c c}^{\prime}}{f_{c o}^{\prime}}=1+3.14 \frac{b}{D} \frac{f_{l}}{f_{c o}^{\prime}} \\
& f_{l}=\frac{2 f_{f r p} t}{D} k_{e}
\end{aligned}
$$

where the diagonal length of the square section $D$ is defined as:

$$
D=\sqrt{2 b}-2 r(\sqrt{2}-1)
$$




\subsubsection{Youssef et al. (2007)}

This model was developed based on comprehensive analysis of experimental results of 87 axially loaded CFRP and GFRP-confined large-scale circular, rectangular and square concrete columns having the unconfined concrete strength of 27.58 to $34.47 \mathrm{MPa}$. The stress-strain curve of tested specimens exhibited a linear behaviour from the stage at which the FRP confinement is fully activated up to the rupture the FRP jacket, and this portion of the curve was observed to be either ascending or descending, depending on the cross-section of the column and the degree of FRP confinement. Based on regression analysis of the tests results, the authors suggested the following linear equations for FRP-confined concrete in circular and rectangular sections.

a. For a circular cross-section with ascending stress-strain response:

$$
\begin{aligned}
& \frac{f_{c u}^{\prime}}{f_{c o}^{\prime}}=2.25\left(\frac{f_{l u}^{\prime}}{f_{c o}^{\prime}}\right)^{\frac{5}{4}} \\
& \varepsilon_{c u}=0.003368+0.2590\left(\frac{f_{l u}^{\prime}}{f_{c o}^{\prime}}\right)\left(\frac{f_{f u}}{E_{f}}\right)^{\frac{1}{2}}
\end{aligned}
$$

b. For a circular cross-section with descending stress-strain response the axial stress and strain are given by:

$$
\begin{aligned}
& \frac{f_{t}}{f_{c o}^{\prime}}=1+3.0\left(\frac{\rho_{f} E_{f} \varepsilon_{f t}}{f_{c o}^{\prime}}\right)^{\frac{5}{4}} \\
& \varepsilon_{t}=0.002748+0.1169\left(\frac{\rho_{f} E_{f} \varepsilon_{f t}}{f_{c o}^{\prime}}\right)^{\frac{6}{7}}\left(\frac{f_{f u}}{E_{f}}\right)^{\frac{1}{2}}
\end{aligned}
$$

c. For a rectangular cross-section with ascending stress-strain response:

$$
\begin{aligned}
& \frac{f_{c c}^{\prime}}{f_{c o}^{\prime}}=0.5+1.225\left(\frac{f_{l u}^{\prime}}{f_{c o}^{\prime}}\right)^{\frac{3}{5}} \\
& \varepsilon_{c u}=0.004325+0.2625\left(\frac{f_{l u}^{\prime}}{f_{c o}^{\prime}}\right)\left(\frac{f_{f u}}{f_{c o}^{\prime}}\right)^{\frac{1}{2}}
\end{aligned}
$$

d. For a rectangular cross-section with descending response, the axial stress and strain are given by:

$$
\begin{aligned}
& \frac{f_{t}}{f_{c o}^{\prime}}=1.0+1.1350\left(\frac{\rho_{f} E_{f} \varepsilon_{f t}}{f_{c o}^{\prime}}\right)^{\frac{5}{4}} \\
& \varepsilon_{t}=0.002+0.0775\left(\frac{\rho_{f} E_{f} \varepsilon_{f t}}{f_{c o}^{\prime}}\right)^{\frac{6}{7}}\left(\frac{f_{f u}}{f_{c o}^{\prime}}\right)^{\frac{1}{2}}
\end{aligned}
$$

where $f_{l u}^{\prime}$ is the effective lateral confining pressure at ultimate condition, $k_{e}$ is the confinement effectiveness coefficient, $\varepsilon_{f t}$ is the strain of FRP jacket at the transition from first to the second region and is taken as 0.002 , and $\rho_{f}$ is the volumetric ratio of FRP.

$$
f_{l u}^{\prime}=k_{e} f_{l u}
$$




$$
k_{e}=\frac{1-\left[\frac{\left(b-2 r_{c}\right)^{2}+\left(h-2 r_{c}\right)^{2}}{3 b h}\right]-\rho_{1}}{1-\rho_{1}}
$$

\subsubsection{ACI Committee 440 Report (2008)}

In this model, the compressive strength and ultimate axial strain of concrete confined by FRP reinforcement are predicted from the equations initially proposed by preceding researchers (Lam and Teng, 2003a; Lam and Teng, 2003b). An additional reduction factor $\psi_{f}$ is included in the proposed equation for the compressive strength $f_{c c}^{\prime}$. This reduction factor assumes a value of 0.95 based on the committee's decision. In this model, the maximum confinement pressure is given by:

$$
f_{l}=\frac{2 E_{f} n t_{f} \varepsilon_{f e}}{D}
$$

where $D$ is the diagonal length of rectangular cross-section, and $\varepsilon_{f e}$ is the effective strain level in FRP at failure.

$$
\begin{aligned}
& D=\sqrt{b^{2}+h^{2}} \\
& \varepsilon_{f e}=k_{\varepsilon} \varepsilon_{f u}
\end{aligned}
$$

where $k_{\varepsilon}$ is the FRP strain efficiency factor taken as 0.586 for CFRP-confined concrete. The maximum compressive strength and ultimate axial strain are given by:

$$
\begin{aligned}
& f_{c c}^{\prime}=f_{c o}^{\prime}+3.3 \psi_{f} k_{a} f_{l} \\
& \varepsilon_{c c}^{\prime}=\varepsilon_{c o}^{\prime}\left[1.5+12 k_{b} \frac{f_{l}}{f_{c o}^{\prime}}\left(\frac{\varepsilon_{f e}}{\varepsilon_{c o}^{\prime}}\right)^{0.45}\right]
\end{aligned}
$$

Being $k_{a}$ and $k_{b}$ the shape factors that depend on the cross-sectional area $A_{e}$ of effectively confined concrete and the side aspect ratio $h / b$ :

$$
\begin{aligned}
& k_{a}=\frac{A_{e}}{A_{c}}\left(\frac{b}{h}\right)^{2} \\
& k_{b}=\frac{A_{e}}{A_{c}}\left(\frac{h}{b}\right)^{0.5}
\end{aligned}
$$

The term $\frac{A_{e}}{A_{c}}$ is expressed as:

$$
\frac{A_{e}}{A_{c}}=\frac{1-\frac{\left[(b / h)\left(h-2 r_{c}\right)^{2}+(h / b)\left(b-2 r_{c}\right)^{2}\right]}{3 A_{g}}-\rho_{g}}{1-\rho_{g}}
$$

\subsubsection{Toutanji et al. (2010)}

Toutanji et al. (2010) studied the behaviour of large-scale rectangular RC columns confined with CFRP under axial loading. The rectangular RC columns had a concrete compressive strength of $38.2 \mathrm{MPa}$, with a cross-sectional area of $125000 \mathrm{~mm}^{2}$ and a height of $2000 \mathrm{~mm}$. The study was part of previous study conducted by Matthys et al. (2005). The results indicate that the overall performance of 
the CFRP-confined concrete columns decreases with increase in the aspect ratio, and the efficiency of FRP confinement directly depends on corner radius of the cross-section. Consequently, two coefficients $\mathrm{k}_{\mathrm{c} 2}$ and $\mathrm{k}_{\mathrm{c} 3}$.are included Richart et al. (1928) model to account for variations in the aspect ratio and corner radius of the cross-section. The proposed strength model that can predict the compressive strength of large-scale rectangular concrete columns confined with FRP jackets is given by:

$$
\begin{aligned}
& f_{c c}^{\prime}=f_{c o}^{\prime}+k_{1} k_{c 2} k_{c 3} f_{l}^{\prime} \\
& f_{l}^{\prime}=k_{e} f_{l}
\end{aligned}
$$

The confinement effectiveness coefficient $k_{e}$ is given by:

$$
k_{e}=\frac{A_{e}}{A_{c}}=1-\frac{(b-2 r)^{2}+(d-2 r)^{2}}{3 A_{g}\left(1-\rho_{s g}\right)}
$$

where $k_{1}=4.0$, and the shape factors $k_{c 2}$ and $k_{c 3}$ are given by:

$$
\begin{aligned}
& k_{c 2}=\left[\frac{2 r}{D}\right]^{0.1} \\
& k_{c 3}=\left[\frac{d}{b}\right]^{0.13}
\end{aligned}
$$

For square concrete cross section, $k_{c 3}=1$

\subsubsection{Benzaid and Mesbah (2014)}

Benzaid and Mesbah (2014) studied the behaviour of 36 axially loaded FRP-confined plain concrete and RC columns of different cross-sections (i.e. circular and square) and different degree of FRP confinement (i.e. zero, one and three layers). The circular columns had a cross-section diameter of $160 \mathrm{~mm}$ and a height of $320 \mathrm{~mm}$ while the short square columns had a cross-section of $140 \mathrm{~mm} \times$ $140 \mathrm{~mm}$ and a height of $280 \mathrm{~mm}$, respectively. The column specimens had a concrete compressive strength of 26, 50 and $62 \mathrm{MPa}$. The results indicate that the efficiency of FRP jackets depends on the cross-section geometry, number of FRP layers and unconfined concrete strength. The results also show that the FRP reinforcement ruptures before reaching its material tensile strength, pointing out that failure of FRP occurs prematurely. Based on these observations, the authors proposed design equations to predict the compressive strength and ultimate axial strain of FRP-confined concrete in circular and square cross-section.

\section{a. Circular Section}

The effective lateral confining pressure is given by:

$$
f_{l, e f f}^{\prime}=\eta f_{l}
$$

where $\eta=0.73$ is the effective FRP strain coefficient obtained by taking the average of circumferential strain at FRP rupture and ultimate tensile strain of FRP reinforcement. The maximum 
compressive strength and ultimate axial strain of FRP-confined concrete are obtained from a regression analysis of experimental test data and are given by:

$$
\begin{aligned}
& \frac{f_{c c}^{\prime}}{f_{c o}^{\prime}}=1+1.60 \frac{f_{l}}{f_{c o}^{\prime}} \\
& \frac{\varepsilon_{c c}}{\varepsilon_{c o}}=2+5.55\left[\frac{f_{l}}{f_{c o}^{\prime}}\right]
\end{aligned}
$$

\section{b. Square Section}

In regard to the square section, a confinement effectiveness factor $k_{e}$ is introduced in quantifying the effective lateral confining pressure as:

$$
f_{l}^{\prime}=k_{e} f_{l}
$$

where $f_{l}$ is the equivalent lateral confining pressure for the square concrete section given by;

- For normal square section

$$
f_{l}=\frac{2 t_{f r p} E_{f r p} \eta^{\prime} \varepsilon_{f u}}{\sqrt{2} \cdot b}
$$

- For a square section with round corners

$$
f_{l}=\frac{2 t_{f r p} E_{f r p} \eta^{\prime} \varepsilon_{f u}}{\sqrt{2} \cdot b-2 R_{c}(\sqrt{2}-1)}
$$

where $\varepsilon_{f u}$ is the ultimate tensile strain of FRP obtained from coupon test, and $\eta^{\prime}$ is the effective FRP strain coefficient accounting for the degree of FRP participation, and the friction between concrete and the bonded FRP jacket. This effective FRP strain coefficient $\eta^{\prime}=68 \%$ is defined as:

$$
\eta^{\prime}=\varepsilon_{h, r u p} / \varepsilon_{f u}
$$

However, the confinement effectiveness coefficient $k_{e}$ is defined as the ratio of effective confinement area $A_{e}$ to the total area of FRP-confined concrete $A_{c}$ :

$$
k_{e}=\frac{A_{e}}{A_{c}}=1-\frac{A_{u}}{A_{g}\left(1-\rho_{s c}\right)}
$$

where $A_{u}$ is the area of unconfined concrete,

- For normal square section

$$
k_{e}=1-\frac{2 b^{2}}{3 A_{g}\left(1-\rho_{s c}\right)}
$$

- For a square section with round corner

$$
k_{e}=1-\frac{2\left(b-2 R_{c}\right)^{2}}{3 A_{g}\left(1-\rho_{s c}\right)}
$$

The compressive strength of FRP-confined concrete for a square section can be calculated by modifying the first strength equation developed by the authors for uniformly confined circular sections with an inclusion of a confinement effectiveness coefficient $k_{e}$. The value of $k_{l}$ is 1.6 and $k_{e}$ is obtained 
from regression analysis of the test results, and it was averagely taken as 0.36 . Therefore, the compressive strength of FRP-confined square concrete columns is given by:

$$
\frac{f_{c c}^{\prime}}{f_{c o}^{\prime}}=1+0.58\left[\frac{f_{l}}{f_{c o}^{\prime}}\right]
$$

Similarly, the ultimate axial strain equation for uniformly confined concrete columns was modified in predicting the ultimate axial strain of FRP-confined square concrete sections, although a different confinement coefficient $k_{e 2}=0.72$ was used. The ultimate axial strain is given by:

$$
\varepsilon_{c c}=\varepsilon_{c o}\left[2+4\left(\frac{f_{l}}{f_{c o}^{\prime}}\right)\right]
$$

\subsubsection{Lim and Ozbakkaloglu (2014)}

This model was developed based on the analytical investigation of axial compressive behaviour of FRP-confined normal and high strength concrete (NSC and HSC) in a square and rectangular cross-section. In this model, some existing theoretical models were first reviewed, and an extensive database containing 484 test results of FRP-confined concrete having square and rectangular cross-section was then collected and studied. The database was then combined with another database containing 1547 test results of axially loaded FRP-confined circular concrete columns. In this model, two sets of equations were proposed, depending on whether the test results exhibited a stress-strain curve in ascending or descending response as shown in Figure-17. Accordingly, a confinement stiffness threshold $k_{1 o}$ was introduced to differentiate between ascending and descending response of stress-strain curve. However, the confinement stiffness threshold is defined as the minimum stiffness of FRP confinement required by the confined concrete to exhibit a stress-strain response with an ascending second branch. For FRP-confined circular sections, $k_{1 o}$ is given by:

$$
\mathrm{K}_{1 \mathrm{o}}=73.7 \mathrm{e}^{0.027 \mathrm{f}_{\mathrm{co}}^{\prime}}
$$

The authors proposed the following expressions to predict the ultimate conditions of FRP-confined concrete.

a. For curves with ascending second branches (i.e. $k_{s l} k_{1} / k_{1 o} \geq 1$ ), the compressive strength and ultimate axial strain are given by:

$$
\begin{aligned}
& f_{c c}^{\prime}=f_{c o}^{\prime}+k_{1}\left(k_{s 1} K_{1}-K_{1 o}\right) \varepsilon_{h, r u p} \\
& \varepsilon_{c u}=c_{2} \varepsilon_{c o}+k_{2} k_{s 2}\left(\frac{K_{1}}{f_{c o}^{\prime}}\right)^{0.9} \varepsilon_{h, r u p}^{1.35}
\end{aligned}
$$

b. For the stress-strain curve with descending second branches (i.e. $k_{s l} k_{1} / k_{1 o}<1$ ), the ultimate axial stress and strain of FRP-confined concrete are given by:

$$
f_{c u}^{\prime}=f_{c o}^{\prime}-k_{1, \text { des }}\left(K_{1 o}-k_{s 1, \text { des }} K_{1}\right) \varepsilon_{h, \text { rup }}
$$




$$
\begin{aligned}
& \varepsilon_{c u}=c_{2} \varepsilon_{c o}+k_{2, \text { des }} k_{s 2, \text { des }}\left(\frac{K_{1}}{f_{c o}^{\prime}}\right)^{0.9} \varepsilon_{h, \text { rup }}^{1.35} \\
& c_{2}=2-\left[\frac{f_{c o}^{\prime}-20}{100}\right], \quad c_{2} \geq 1 \\
& K_{1}=\frac{2 E_{f} t_{f}}{d_{e}} \\
& d_{e}=\sqrt{\left(h^{2}+b^{2}\right) / 2}
\end{aligned}
$$

where $c_{2}$ is the concrete strength factor; $d_{e}$ is the equivalent cross-sectional dimension of square and rectangular sections; $k_{1}$ is the confinement stiffness; $k_{1}$ and $k_{2}$ are the strength and strain enhancement coefficients and are taken as 4.1 and $0.27 ; k_{1, d e s}$ and $k_{2, d e s}$ are the strength decay and strain enhancement coefficients for circular columns having a stress-strain curve with descending second branches and are averagely taken as 4.5 and $0.27 ; k_{s 1}$ and $k_{s 2}$ are the strength and strain efficiency factors for a stress-strain curve with ascending second branches; $k_{s 1, d e s}$ and $k_{s 2 \text {,des }}$ are the strength and strain efficiency factors for a stress-strain curve with descending second branches, and $\varepsilon_{h, \text { rup }}$ is the hoop rupture strain FRP.

$$
\begin{aligned}
& k_{s 1}=\left(\frac{2 r}{d_{e}}\right)^{0.67}\left(\frac{h}{b}\right)^{-0.5} \\
& k_{s 2}=\left(2-\frac{2 r}{d_{e}}\right)^{2}\left(\frac{2 r}{d_{e}}\right)\left(\frac{h}{b}\right)^{0.22} \\
& k_{s 1, \text { des }}=k_{s 1} \quad \text { for } \quad \frac{2 r}{d_{e}} \geq 0.15 \\
& k_{s 2, \text { des }}=\left(\frac{2 r}{d_{e}}\right)^{-0.26}\left(\frac{h}{b}\right)^{0.22} \text { for } \quad \frac{2 r}{d_{e}} \geq 0.15 \\
& \varepsilon_{h, \text { rup }}=k_{\varepsilon, f} \varepsilon_{f} \\
& k_{\varepsilon, f}=0.9-2.3 f_{c o}^{\prime} \times 10^{-3}-0.75 E_{f} \times 10^{-6}
\end{aligned}
$$

where $\varepsilon_{f}$ is the ultimate tensile strain of FRP, $k_{\varepsilon, f}$ is the hoop strain reduction factor developed by Ozbakkaloglu and Lim (2013), and $E_{f}$ is the elastic modulus of FRP.

$$
100000 M P a \leq E_{f} \leq 640000 M P a
$$

The peak axial strain of unconfined concrete is evaluated using the equation proposed by Tasdemir et al. (1998).

$$
\varepsilon_{c o}=\left(-0.06 f_{c o}^{\prime 2}+29.9 f_{c o}^{\prime}+1053\right) \times 10^{-6}
$$




\subsubsection{Faustino et al. (2014)}

Faustino et al. (2014) investigated the compressive behaviour of square concrete columns wrapped with CFRP by adapting a model developed by Chastre and Silva (2010) for concrete columns with a circular section. According to Chastre and Silva (2010) model, the peak stress of FRP-confined concrete is expressed as a function of the unconfined concrete strength $f_{c o}$ and the lateral confining pressure $f_{l u}$ :

$$
f_{c c}=f_{c o}+k_{1} f_{l u}
$$

Where, $k_{l}$ is taken as 5.29 for circular columns. Accordingly, Faustino et al. (2014) modified the above equation for FRP-confined square concrete columns by considering the influence of the section corner radius and using the experimental results of CFRP-confined square concrete columns with $k_{1}=3.7$ :

$$
f_{c c}=f_{c o}+3.7\left(\frac{2 R}{B}\right) f_{l}
$$

In addition to FRP lateral confinement, the model also considers the lateral confinement provided by steel hoops. Therefore, the combined lateral confinement $f_{l u}$ is given by:

$$
\begin{aligned}
& f_{l u}=f_{j u}+f_{s h u} \\
& f_{j u}=\frac{2 t}{B} E_{f} \varepsilon_{l u} \\
& f_{s h u}=\frac{2 A_{s w}}{d_{w} s} f_{s w}
\end{aligned}
$$

where $t$ is the thickness of FRP, $E_{f}$ is Young's modulus of FRP, $B$ is the diameter of an equivalent circular cross-section, $A_{s w}$ and $d_{w}$ are the cross-section area and diameter of steel hoops, $s$ is the spacing between the steel hoops, and $f_{s w}$ is the tensile strength of steel hoops and is assumed to be constant after yielding of steel. The tensile strength of steel hoops is related to the column lateral strain $\varepsilon_{l u}$ and Young's modulus $E_{s}$ by:

$$
f_{s w}= \begin{cases}E_{s} \times \frac{d_{w}}{B} \varepsilon_{l u} & \text { for } \varepsilon_{l u}<\frac{B}{d_{w}} \varepsilon_{y} \\ f_{y} & \text { for } \varepsilon_{l u} \geq \frac{B}{d_{w}} \varepsilon_{y}\end{cases}
$$

Faustino et al. (2014) proposed the following equation to predict the lateral strain $\varepsilon_{l u}$ of square concrete columns confined with FRP by considering the effect of the corner radius of the column section (Mirmiran and Shahawy, 1997).

$$
\varepsilon_{l u}=0.7\left(\frac{2 R}{B}\right)^{0.23} \varepsilon_{f u}
$$

where $\varepsilon_{f u}$ is the rupture strain of CFRP. 
Based on the regression analysis of test data of square concrete columns confined with FRP, the authors propose the following equation to predict the peak axial strain $\varepsilon_{c c}$ of a column by revising the model proposed by Chastre and Silva (2010) for circular RC columns confined with FRP.

$$
\varepsilon_{c c}=18.89 \varepsilon_{c o}\left(\frac{f_{l u}}{f_{c o}}\right)
$$

where $\varepsilon_{c o}$ is the axial strain of unconfined concrete at peak load given by (BS EN 1992-1-1, 2004):

$$
\varepsilon_{c o}=\frac{0.7}{1000}\left[f_{c o}\right]^{0.31}
$$

\subsection{Confinement Models for Eccentrically Loaded FRP-Confined Circular Concrete Columns}

\subsubsection{Fam et al. (2003)}

Fam et al. (2003) investigated the behaviour of concrete-filled GFRP circular tubes subjected to concentric and eccentric axial loads as well as pure bending. The results of the study demonstrate that increasing the load eccentricity can significantly reduce the level of confinement in FRP tubes due the strain gradient that subjects large part of the cross-section to tensile strains as shown in Figure-18. Based on this observation, the authors proposed a variable confinement model to predict the ultimate strength $\overline{f_{c c}}$ of FRP-confined concrete;

$$
\overline{f_{c c}}=\left(f_{c c}^{\prime}-f_{c c o}\right)\left[\frac{D_{o}}{D_{o}+e}\right]+f_{c c o}
$$

where $D_{o}$ is the outer diameter; $e$ the load eccentricity, and $f_{c c o}$ is the unconfined concrete stress at the ultimate strain corresponding to $\varepsilon_{c c o}$. For pure axial load $(e=0), \overline{f_{c c}}=f_{c c}^{\prime}$, for pure bending $(\mathrm{e}=\infty)$, $\overline{f_{c c}}=f_{c c o}$.

Moreover, a strain model was also proposed to predict the ultimate axial strain $\overline{\varepsilon_{c c}}$, which corresponds to the strength $\overline{f_{c c}}$ based on Tsai-Wu bi-axial strength failure criteria for FRP materials (Fam and Rizkalla, 2001). The ultimate axial strain is given by:

$$
\overline{\varepsilon_{c c}}=\left(\varepsilon_{c c o}-\varepsilon_{c c}^{\prime}\right) \sqrt{1-\left(\frac{\overline{f_{c c}}-f_{c c o}}{f_{c c}^{\prime}-f_{c c o}}\right)^{2}+\varepsilon_{c c}^{\prime}}
$$

where $\varepsilon_{c c o}$ is the ultimate axial compressive strain of concrete, which equals to the ultimate axial strain of FRP tube in compression, and $\varepsilon_{c c}^{\prime}$ is the axial strain of concrete corresponding to $f_{c c}^{\prime}$.

\subsubsection{Cao et al. (2018)}

Cao et al. (2018) investigated the influence of different load paths on the stress-strain behaviour of eccentrically loaded circular concrete columns confined with FRP composites. As illustrated in Figure-19, the typical load paths include: (I) increasing axial load $N$ with a constant eccentricity of loading $e$, (II) constant axial force with increasing bending moment $M$ or eccentricity of loading, and (III) constant bending moment with increasing axial force. The work reveals that the 
post-peak slope of the stress-strain response of FRP-confined concrete columns under load path II increases with increasing axial force and decreases with increasing eccentricity of loading. The authors propose a stress-strain model for FRP-confined circular concrete columns under constant axial force and increasing bending moment (i.e., load path II). The model was developed based on the experimental test results from $\mathrm{Wu}$ and Cao (2017). However, a typical unified constitutive model (Equation (35a)) proposed by Zhou and Wu (2012) was used to develop the model (Figure-20). This model was selected due to its suitability for stress-strain modelling of FRP-confined concrete.

$$
\sigma_{z}=\left[\left(E_{1} \varepsilon_{n}-f_{o}\right) e^{-\frac{\varepsilon_{Z}}{\varepsilon_{n}}}+f_{o}+E_{2} \varepsilon_{z}\right]\left(1-e^{-\frac{\varepsilon_{Z}}{\varepsilon_{n}}}\right)
$$

where $\sigma_{z}$ is longitudinal stress corresponding to the longitudinal strain $\varepsilon_{z}, E_{1}$ is the initial tangent modulus of concrete, $E_{2}$ is the slope of the asymptotic line of the second part of the stress-strain curve after the turning point, $f_{o}$ is the intercept of the asymptotic line on the y-axis, and $n$ is a parameter that accounts for the curvature of the transition zone, with $\varepsilon_{n}$ given by:

$$
\varepsilon_{n}=n \frac{f_{o}}{E_{1}}
$$

Among the four parameters in Equation (35a), $E_{1}$ was taken as the elastic modulus of concrete $E_{c}$, and $n$ was obtained from the experimental stress-strain curves for concentrically loaded columns. However, the remaining two parameters, $E_{2}$ and $f_{o}$, are defined as functions of concrete strength, confinement stiffness, axial force, and load eccentricity:

$$
\begin{aligned}
& \frac{E_{2}}{E_{2,0}}=f\left(\frac{E_{l}}{E_{c}}, \frac{f_{c o}}{f_{30}}, \frac{N}{f_{c o} A}, \frac{M}{N r}\right) \\
& \frac{f_{o}}{f_{o, 0}}=\varnothing\left(\frac{E_{1}}{E_{c}}, \frac{f_{c o}}{f_{30}}, \frac{N}{f_{c o} A}, \frac{M}{N r}\right) \\
& E_{l}=\frac{2 E_{f} t_{f}}{D}
\end{aligned}
$$

where $E_{l}$ is the confinement stiffness as defined in Equation (35e), $E_{f}$ and $t_{f}$ are the stiffness and thickness of FRP jacket, $f_{c o}$ is the unconfined concrete strength, $f_{30}$ is the strength of grade 30 concrete $\left(f_{30}=30 M P a\right), E_{c}$ is defined as $4730 f_{30}{ }^{0.5}, r$ is the radius of the concrete cross-section, and the parameters $E_{2,0}$ and $f_{o, 0}$ are obtained from regression analysis of a stress-stress model proposed by Wei and $\mathrm{Wu}$ (2012) for concentrically loaded FRP-confined concrete columns. The expressions for $E_{2}$ and $f_{o}$ are given by:

$$
\begin{aligned}
& \frac{E_{2}}{E_{2,0}}=1-0.58\left(\frac{E_{l}}{E_{c}}\right)^{-0.29}\left(\frac{M}{N r}\right)^{0.28}\left(\frac{f_{C o}}{f_{30}}\right)^{0.47}\left(1-\left(\frac{N}{N_{u}}\right)^{1.76}\right) \\
& \frac{f_{o}}{f_{o, 0}}=1-1.27\left(\frac{E_{l}}{E_{c}}\right)^{0.32}\left(\frac{M}{N r}\right)^{0.60}\left(\frac{f_{C o}}{f_{30}}\right)^{0.32}\left(1-\left(\frac{N}{N_{u}}\right)^{0.21}\right)^{\alpha} \\
& \alpha=-10\left(\left[\frac{f_{c o}}{f_{30}}\right]^{-3}\left[\frac{E_{l}}{E_{c}}\right]^{1.1}+0.027\right)
\end{aligned}
$$

where $N_{u}$ is the load capacity of confined concrete given by;

$$
N_{u}=f_{c c} A=f_{c o} A k_{1}
$$


where $A$ is the area of the column and $f_{c c}$ is the compressive strength of FRP-confined concrete estimated based on Wei and Wu's ( 2012) model;

$$
\begin{aligned}
& f_{c c}=f_{c o}\left(1+2.2\left(\frac{f_{l}}{f_{c o}}\right)^{0.94}\right) \\
& k_{1}=1+2.2\left(\frac{f_{l}}{f_{c o}}\right)^{0.94}
\end{aligned}
$$

\subsection{Confinement Models for Eccentrically Loaded FRP-Confined Non-Circular Concrete} Columns

\subsubsection{Maaddawy (2009)}

Maaddawy (2009) studied the experimental and analytical behaviour of eccentrically loaded CFRP-wrapped square RC columns with end corbels and having a concrete compressive strength of 28.5 $\pm 2.5 \mathrm{MPa}$. The parameters investigated include wrapping conditions (i.e. no-FRP-wrapping, partial FRP-wrapping and full FRP-wrapping) and eccentricity to height ratio e/h (i.e. $0.3,0.43,0.57$ and 0.86). The results show that the ultimate compressive strain enhancement caused by CFRP confinement was inversely proportional to the load eccentricity ratio, indicating that the level of FRP confinement has gradually reduced due to the increased load eccentricity ratio. The author suggested the following equations for the compressive strength and ultimate axial strain of CFRP-confined concrete under eccentric loading.

$$
\begin{aligned}
& f_{c c}^{\prime}=f_{c o}^{\prime}+\left(f_{c c o}^{\prime}-f_{c o}^{\prime}\right)\left[\frac{1}{1+e / h}\right] \\
& \varepsilon_{c c}=\varepsilon_{c u}+\left(\varepsilon_{c c u}-\varepsilon_{c u}\right)\left[\frac{1}{1+e / h}\right]
\end{aligned}
$$

where $f_{c c o}^{\prime}$ and $\varepsilon_{c c u}$ are the compressive strength and ultimate compressive strain of CFRP-confined concrete under concentric loading (Teng et al., 2002).

$$
\begin{aligned}
& f_{c c o}^{\prime}=f_{c o}^{\prime}\left[1+2 \frac{f_{l}}{f_{c o}^{\prime}}\right] \\
& \varepsilon_{c c u}=\varepsilon_{c o}\left[1.75+10 \frac{f_{l}}{f_{c o}^{\prime}}\right]
\end{aligned}
$$

The effective lateral confining pressure is given by:

$$
f_{l}=k_{s} \frac{2 f_{f r p} t_{f e}}{\frac{1}{2}(b+h)}
$$

where $t_{f e}$ is the effective thickness of CFRP laminate and $k_{s}$ is a shape factor;

$$
\begin{aligned}
& t_{f e}=\left\{\begin{array}{cc}
t_{f}, & \text { For full wrapping } \\
\frac{w_{f}}{s_{f}} t_{f} & \text { For Partial wrapping }
\end{array}\right. \\
& \mathrm{k}_{\mathrm{s}}=\left[1-\frac{\left(\mathrm{b}-2 \mathrm{R}_{\mathrm{c}}\right)^{2}+\left(\mathrm{h}-2 \mathrm{R}_{\mathrm{c}}\right)^{2}}{3 \mathrm{~A}_{\mathrm{g}}}-\rho_{\mathrm{s}}\right] /\left(1-\rho_{\mathrm{s}}\right)
\end{aligned}
$$




\section{FINITE ELEMENT ANALYSIS}

In addition to experimental studies and confinement models, some researchers (Malvar et al., 2004; Yu et al., 2010; Karabinis et al., 2008; Zeng et al., 2018; Parghi and Alam, 2017; Parghi and Alam, 2016; Chellapandian et al., 2018; Lin and Teng, 2017; Feng et al., 2002; Hajsadeghi et al., 2011; Chakrabarti et al., 2008; Mostofinejad and Saadatmand, 2010; Wu et al., 2009; Hu et al., 2011; Mirmiran et al., 2000) have also performed numerical investigations to understand the overall behaviour of FRP-confined concrete columns using the finite element method (FEM). The FEM is a numerical method that solves the governing ordinary and partial differential equations of a system through the discretisation process. The method is increasingly gaining popularity as a tool in the modelling of both uniformly and non-uniformly confined concrete columns, as it is capable of capturing complex stress distribution in concrete section planes. Previous studies have revealed that finite element analysis (FEA) could efficiently simulate the behaviour of FRP-confined concrete columns when an accurate numerical model is used (Yu et al., 2010; Feng et al., 2002).

Mirmiran et al. (2000) used a non-linear FEM to simulate the cyclic response of circular and square concrete columns confined by FRP composites using ANSYS software. They adopted a nonassociative Drucker-Prager plasticity model, which accounts for the pressure sensitivity of concrete. The predicted stress-strain response of the columns indicates a positive correlation with the results obtained by the researchers in their experimental study (Figure-21). Nevertheless, the FEA results also reveal a similar stress concentration around the corners of the square concrete section, as determined in the experimental study. However, Feng et al. (2002) reported a similar observation.

Malvar et al. (2004) performed a numerical analysis on concrete cylinders and prisms confined with different FRP materials (aramid, carbon, and glass). The model was developed using an explicit finite element (FE) code from DYNA3D with a concrete material model initially developed for blast analysis. The FEA results agree favourably with the experimental test results regarding strength enhancement for specimens with various degrees of FRP confinement. The authors confirm that FRP wrapping is an effective measure to improve the structural integrity of columns subjected to seismic and blast loadings.

Karabinis et al. (2008) performed 3D-FEA to evaluate the influence of FRP sheet confinement on the elastic buckling of longitudinal steel bars in old-type square RC columns with deficient concrete strength and stirrup spacing subjected to compressive loading. The square RC columns had cross-sections measuring $200 \mathrm{~mm} \times 200 \mathrm{~mm}$ with a rounded corner radius of $30 \mathrm{~mm}$. The specimens were reinforced with $14 \mathrm{~mm}$-diameter bars as longitudinal reinforcement and $6 \mathrm{~mm}$-diameter steel stirrups spaced at 200mm with CFRP as the external confining material. The 3D non-linear FEA was carried out in the ABAQUS (HKS 1997) FE program, and concrete behaviour was modelled with a Drucker-Prager-type material and non-associative flow rule. External CFRP confinement was found to 
be effective in enhancing the mechanical behaviour of the RC columns by providing adequate lateral confinement and hence preventing buckling of the longitudinal steel bars.

Chakrabarti et al. (2008) developed an efficient non-linear FE model for the analysis of plain and RC columns in circular and square sections confined by FRP sheets under axial loading. The model was carried out using ANSYS FE software. They used SOLID65, SOLID46, and LINK8 elements to model concrete, FRP composites, and steel reinforcements. Considering the symmetry and loading, only a quarter-section of the circular columns was modelled. The FEA results reveal that externally bonded FRP significantly enhances the strength and ductility of the columns, with greater enhancement as the number of FRP layers increases. The study also found that the efficiency of the FRP confinement was more effective for columns with low concrete grades.

Wu et al. (2009) performed a 3D non-linear FEA to simulate the behaviour of aramid FRP (AFRP)-confined HSC columns using ANSYS FE software. The specimens are $100 \mathrm{~mm}$ in diameter and $300 \mathrm{~mm}$ in height and were made with three concrete grades of 46.43, 78.50, and 101.18MPa. The concrete core was modelled with an eight-node SOLID65 element, which is capable of cracking under tension and crushing under compression and has excellent resistance to plastic deformation. A fournode SHELL41 element was used to model the AFRP sheets. The results of the non-linear analysis show that columns with continuous AFRP wrapping experienced a significant increase in strength and ductility, whereas an increase in strength only was observed in columns with partial AFRP wrapping.

Hu et al. (2011) used the ANSYS FEA analysis to develop two non-linear FE models (FEM1 and FEM2) that could simulate the behaviour of FRP-wrapped RC columns under eccentric loading. In these two models, the failure behaviour of confined concrete was simulated using the WilliamWarnke failure criterion (Willam and Warnke, 1975). Two methods were employed to simulate the interfaces between concrete and the confining FRP composite for strength prediction. In the first method (FEM1), the contact elements TARGET170 and CONTA174 were used to connect concrete and FRP composite elements, whereas a perfect bond was assumed between concrete and FRP composite in the second method (FEM2). The numerical FEA results agreed with the experimental results for both FE models. The FEA results indicate that a perfect bond could efficiently simulate the interface between concrete and FRP as well as the interface elements. The authors concluded that the maximum concrete compressive stress and strain of the eccentrically loaded columns depends on the unconfined concrete strength as well as the level of confinement provided by external FRP composites.

Parghi and Alam (2016) performed a non-linear static pushover analysis on seven parameters that influenced the seismic behaviour of deficient circular RC bridge piers confined with CFRP composites using a three-level fractional factorial design method. These factors included the 
compressive strength of concrete, yield strength of steel, longitudinal steel reinforcement ratios, spacing of stirrups, axial load, shear span-depth ratio, and number of FRP layers, as depicted in Table1. The authors used Seismostruct, a non-linear analysis program (SeismoStruct, 2015) to model the geometry of the bridge piers as a 2D FE frame. The results of the findings reveal that lateral loadcarrying capacity, ductility, and the failure mechanism of the strengthened columns are significantly influenced by the shear span-depth ratio, yield strength of steel, longitudinal reinforcement ratio, axial load, and confining FRP reinforcement. Subsequently, Parghi and Alam (2017) reported similar results in their vulnerability study of non-seismically designed circular RC bridge piers retrofitted with CFRP composites.

Chellapandian et al. (2018) carried out numerical and analytical investigations to evaluate the influence of hybrid strengthening on initial post-cracking stiffness, peak and post-peak behaviour, and the failure mechanism of square RC columns subjected to axial and eccentric loadings. The numerical model was developed using ABAQUS software and it was compared with the experimental test results. The results reveal that the non-linear FE model was able to capture the overall behaviour of the strengthened and unstrengthened RC columns under axial and eccentric loadings. The authors concluded that the hybrid FRP strengthening is effective in enhancing initial post-cracking stiffness, strength, and ductility of the strengthened RC columns under both loading conditions.

Zeng et al. (2018) studied the behaviour of cylindrical concrete columns partially wrapped with CFRP strips under concentric loading. They also proposed a three-dimensional FE approach for modelling circular concrete columns partially wrapped with FRP reinforcement. The model was developed in ABAQUS based on a constitutive concrete damage-plastic model (CDPM). The authors reported that trends of axial and hoop strain distributions observed in the FE approach are in accordance with the experimental observations. It was also revealed that axial and hoop strain are larger at the mid-plane of the two adjacent FRP strips than at the mid-plane of each FRP strip.

\section{DISCUSSION}

\subsection{Previous Experimental Studies}

This review presents a significant number of empirical investigations to understand the influence of various test parameters on the behaviour and performance of axially and eccentrically loaded FRP-confined circular and non-circular concrete columns. These parameters include the number of FRP layers (FRP thickness), concrete compressive strength, presence of a corner radius, and magnitude of load eccentricity.

The review shows that the rate at which the strength and ductility of the FRP-confined concrete columns increase primarily depends on the number of FRP layers (i.e., FRP stiffness), regardless of whether the column section is circular or non-circular and under axial or eccentric loading. Chaallal et 
al. (2003) confined rectangular concrete columns with between zero and four layers of CFRP. A strength enhancement of $90 \%$ was observed in rectangular concrete columns confined with four layers of CFRP. Berthet et al. (2005) used between two and 12 layers of CFRP and GFRP wraps to strengthen concrete cylinders. The researchers observed a substantial enhancement in load-carrying capacity, and structural ductility of the FRP-confined concrete cylinders as the level of confinement increased. In their investigation, Wang and Wu (2008) and Parvin and Wang (2001) used similar confinement levels of one and two layers of CFRP to wrap square concrete column specimens. The authors observed a significant improvement in strength and ductility of the strengthened columns with an increase in the number of CFRP layers. The CFRP-confined concrete columns with two layers demonstrated a strength enhancement double that of CFRP-confined concrete columns with one layer. Furthermore, Almusallam (2007) wrapped concrete cylinders with one and three layers of GFRP laminates and observed a compressive strength gain of up to $110 \%$ in GFRP-confined concrete cylinders with three layers. Other researchers (Matthys et al., 2006; Li and Hadi, 2003; Hadi and Li, 2004; Sadeghian et al., 2010; Kumutha et al., 2007) have also confirmed that the efficiency of FRP confinement can be improved by increasing the stiffness (layers) of FRP jackets.

The compressive strength of concrete is one of the fundamental parameters investigated by previous studies on FRP-confined concrete. Most of the studies reported in this review confirm that the effectiveness of confining FRP is essentially influenced by the compressive strength of concrete in the inner core. However, this phenomenon is yet to be investigated in detail by researchers. For both circular and non-circular concrete sections, the efficiency of the confining FRP decreases with an increase in concrete compressive strength. Chaallal et al. (2003) observed a $90 \%$ gain in strength and ductility for wrapped columns with concrete compressive strength of $20.7 \mathrm{MPa}$ compared to a $30 \%$ increase in performance for FRP-wrapped columns with concrete compressive strength of 41.4MPa. Furthermore, Almusallam (2007) reported a strength and ductility enhancement of $78.7 \%$ for wrapped columns with three layers and concrete compressive strength of $50.8 \mathrm{MPa}$ while a $16.1 \%$ gain was recorded for columns with a similar level of confinement but concrete compressive strength of 107.8MPa. The experimental investigation conducted by Berthet et al. (2005) shows that the efficiency of FRP confinement tends to diminish with an increase in concrete core strength. The authors observed a 15\% decrease in confinement efficiency for FRP-confined concrete with 100MPa compressive strength and a $25 \%$ decrease for FRP-confined concrete with compressive strength of 200MPa. Furthermore, Benzaid and Mesbah (2014) observed 46\% and 24\% enhancement in the ultimate strength of normal and HSC wrapped columns with three layers of CFRP.

Regarding the influence of corner radius in non-circular concrete sections, research (Mirmiran et al., 1998; Ozbakkaloglu and Oehlers, 2008; Al-Salloum, 2007; Wang and Wu, 2008) has shown that the presence of sharp edges can lead to the variation in the confining pressure produced by FRP to the 
concrete core from a maximum at the corners to a minimum along the edges of a section. These variations in confining pressure result in premature failure of the confining FRP, which mostly commences at or near the corners of a section due to the concentration of stress in the region. Consequently, FRP confining pressure is insufficient to improve the strength and ductility of columns. However, to improve strength and ductility and prevent premature failure of FRP, researchers have recommended that the sharp edges should be rounded. Accordingly, further investigation should be conducted to better understand the significance of rounded corners on the performance of eccentrically loaded FRP-confined concrete columns.

In regard to the effect of load eccentricity, the behaviour of eccentrically loaded FRP-confined concrete columns is different from that of axially loaded columns because the eccentricity of loading causes variation across a section in the confining pressure provided by the FRP. Further, significant experimental results involving eccentrically loaded FRP-confined concrete columns are also reported in the review (Ghali et al., 2003; Hadi, 2009; Wu and Jiang, 2013; Parvin and Wang, 2001; Hadi and Widiarsa, 2012; Widiarsa and Hadi, 2013; Fam et al., 2003; Maaddawy, 2009). The results show that eccentricity of loading could lead to a decrease in the strength of FRP-confined concrete columns in both circular and non-circular sections.

\subsection{Previous Confinement Models}

It is apparent that a substantial number of experimental studies presented in the review involving axially and eccentrically loaded FRP-confined columns in circular and non-circular sections have resulted in numerous confinement models. Some of the models were developed based directly on the experimentally observed stress-strain response of FRP-confined concrete columns (Matthys et al., 2006; Al-Salloum, 2007; Benzaid and Mesbah, 2014; Youssef et al., 2007; Toutanji, 1999; Samaan et al., 1998; Mirmiran and Shahawy, 1997; Saafi et al., 1999; Shehata et al., 2001; Kumutha et al., 2007; Toutanji et al., 2010; Fam et al., 2003). Conversely, other models were developed based on analysis of databases containing extensive test results from previous experimental investigations (Lam and Teng, 2003a; Lam and Teng, 2003b; Saadatmanesh et al., 1994; Karbhari and Gao, 1997; Lam and Teng, 2002; Ozbakkaloglu and Lim, 2013; Wu and Wei, 2014; Wu et al., 2007; Lim and Ozbakkaloglu, 2014). Most of these models have adopted the general expressions proposed by Richart et al. (1928) for the determination of the strength enhancement ratio $\left(f_{c c}^{\prime} / f_{c o}^{\prime}\right)$ and the strain enhancement ratio $\left(\varepsilon_{c c} / \varepsilon_{c o}\right)$ of FRP-confined concrete. These expressions are given as a linear or non-linear function of the effective confinement ratio $\left(f_{l} / f_{c o}^{\prime}\right)$.

Researchers have assessed the performance of these confinement models for reliable prediction of ultimate strength and strain of FRP-confined concrete (Wu and Jiang, 2013; Lam and Teng, 2003b; Ozbakkaloglu et al., 2013). However, the performance assessment of existing confinement models has 
shown that most of the models either underestimate or overestimate the compressive strength and ultimate strain of FRP-confined concrete. Among the confinement models assessed by Marques and Chastre (2012), Chastre and Silva (2010) model was found to be the most accurate predictive model for load-strain relations as well as dilation behaviour. Moreover, Faustino and Chastre (2015) conducted a comparative analysis of six confinement models with seven experimental results of axially loaded FRP-confined square RC columns. The authors found that among the six confinement models, Faustino et al.'s (2014) model provided the best correlation with the experimental results for columns with a larger cross-section. However, for columns with a small cross-section, none of the models provided an accurate prediction. Furthermore, Ozbakkaloglu et al. (2013) pointed out that confinement models developed using the actual FRP hoop rupture strain $\left(\varepsilon_{h, \text { rup }}\right)$ performed significantly better than those predicted using the ultimate tensile strain of fibres $\left(\varepsilon_{f}\right)$.

It is apparent that there are extensive investigations on the stress-strain behaviour of concentrically loaded FRP-confined concrete columns and is better understood compared to the same for eccentrically loaded columns. For this reason, further investigation of the stress-strain behaviour of eccentrically loaded FRP-confined concrete columns should be conducted to better understand the variation in sufficient FRP confinement over the column section.

\section{CONCLUSIONS}

This paper presents a general review of experimental and analytical studies on the behaviour and performance of FRP-confined concrete columns in both circular and non-circular cross-sections subjected to concentric and eccentric compressive loadings. At the outset, the behaviour and mechanics of FRP confinement in circular and non-circular concrete sections are reviewed. Then, existing theoretical models developed based on experimental studies conducted by various researchers to predict the compressive strength and ultimate axial strain of FRP-confined concrete are reviewed. The review demonstrates that the performance and effectiveness of FRP confinement in concrete columns have been extensively investigated and the technique has been proven effective in enhancing the structural performance and ductility of strengthened column structures, as it provides confinement to the concrete core. The following conclusions can be drawn from the review.

- The review shows that the failure of FRP-confined concrete columns occurs suddenly and violently, resulting in the rupture of FRP composites. The rupture of FRP in cylindrical column sections usually commences at or near mid-height and then propagates towards the other ends of the column. However, unlike circular concrete columns, FRP rupture in non-circular column sections initiates at or near the corners of the section. This is attributed to the concentration of strain at the corners of the section. 
- FRP confinement effectiveness is uniform in circular columns subjected to axial loads. However, in non-circular (square/rectangular) columns, the confining pressure provided by the FRP jacket varies over the cross-section, and only part of the concrete is adequately confined. This variation in confining pressure results in excessive reduction in confinement efficiency.

- The confinement effectiveness provided by FRP depends on the number of FRP layers and concrete compressive strength. The higher the number of FRP layers, the greater the increase in confinement effectiveness. Likewise, the confinement efficiency is greater in columns with lower or normal concrete compressive strength.

- For eccentrically loaded FRP-confined concrete columns, the ultimate load-carrying capacity depends on the magnitude of load eccentricity. An increase in the load eccentricity results in a decrease in the ultimate capacity of the column.

- The reviewed experimental studies show that the confining FRP in FRP-confined concrete ruptures at tensile strain lower than the original FRP material tensile strain. By this observation, the effective confining pressure in confinement models should be preferably based on the hoop rupture strain of FRP than the FRP material tensile strain.

- From the reviewed confinement models, it is evident that the stress-strain curve of axially loaded FRP-confined concrete columns explicitly demonstrated a bi-linear response. However, the presence of eccentricity in eccentrically loaded FRP-confined concrete columns affects the stressstrain relationship because load eccentricity could lead to variation in the effective confinement pressure across the column section. Consequently, the stress-strain relationship adopted for axially loaded FRP-confined concrete is not directly applicable to eccentrically loaded FRP-confined concrete.

- Ultimately, the accuracy of FRP confinement models still needs to be investigated because the performance of most confinement models results in either underestimating or overestimating the compressive strength and ultimate strain of FRP-confined concrete.

\section{References}

ACI Committee 440 Report, 2008. "Guide for the Design and Construction of Externally Bonded FRP Systems for Strengthening Concrete Structures" ACI 440.2R., Farmington Hills, USA.

Alecci, V., Briccoli Bati, S. and Ranocchiai, G., 2014. "Concrete columns confined with CFRP wraps". Materials and Structures/Materiaux et Constructions, 47(3), pp.397-410.

Almusallam, T.H., 2007. "Behavior of normal and high-strength concrete cylinders confined with Eglass/epoxy composite laminates". Journal of Composites Part B: Engineering, 38(5-6), pp.629639.

Al-Salloum, Y.A., 2007. "Influence of edge sharpness on the strength of square concrete columns 
confined with FRP composite laminates". Journal of Composites Part B: Engineering, 38(5-6), pp.640-650.

Amrul Kaish, A.B.M. Alam, M.R., Jamil, M. and Wahed, M.A., 2013. "Ferrocement jacketing for restrengthening of square reinforced concrete column under concentric compressive load". Procedia Engineering, 54, pp.720-728.

Artoglu, N., Girgin, Z.C. and Artoglu, E., 2006. "Evaluation of Ratio between Splitting Tensile Strength and Compressive Strength for Concretes up to $120 \mathrm{MPa}$ and its Application in Strength Criterion". ACI Materials Journal, 103(1), pp.18-24.

Attard, M.M. and Setunge, S., 1996. "Stress-strain relationship of confined and unconfined concrete". ACI Materials Journal, 93(5), pp.432-442.

Azadeh, Parvin and Wei, Wang, 2001. "Bahaviour of FRP Jacketed Concrete Columns under Eccentric Loading". Journal of Composite for Construction, 5(3), pp.146-152.

Benzaid, R. and Mesbah, H.-A., 2014. "The confinement of concrete in compression using CFRP composites-effective design equations". Journal of Civil Engineering and Management, 20(5), pp.632-648.

Berthet, J.F., Ferrier, E. and Hamelin, P., 2005. "Compressive behavior of concrete externally confined by composite jackets: Part A: Experimental study". Journal of Construction and Building Materials, 19(5), pp.223-232.

Bousias, S., Spathis, A.-L. and Fardis, M.N., 2007. "Seismic Retrofitting of Columns with Lap Spliced Smooth Bars Through FRP or Concrete Jackets". Journal of Earthquake Engineering, 11(5), pp.653-674.

Bousias, S.N., Spathis, A.-L. and Fardis, M.N., 2006. "Concrete or FRP Jacketing of Columns with Lap Splices for Seismic Rehabilitation". Journal of Advanced Concrete Technology, 4(3), pp.431-444.

BS EN 1992-1-1, 2004. Eurocode 2: Design of concrete structures - Part 1-1: General rules and rules for buildings, Brussels.

Campione, G., 2012. "Load carrying capacity of RC compressed columns strengthened with steel angles and strips". Engineering Structures, 40, pp.457-465.

Cao, Y., Wu, Y.-F. and Jiang, C., 2018. "Stress-strain relationship of FRP confined concrete columns under combined axial load and bending moment". Composites Part B: Engineering, 134, pp.207217.

Chaallal, O., Shahawy, M. and al-Saad, A., 2000. "Behaviour of Axially Loaded Short Rectangular Columns Strengthened With CFRP Composite Wrapping". Technical Report, FDOT, Structures Research Center, (August 2000).

Chaallal, O., Hassan, M. and Shahawy, M., 2003. "Performance of axially loaded short rectangular columns strengthened with fiber-reinforced polymer wrapping". Journal of Composites for 
Construction, 7(3), pp.200-208.

Chakrabarti, A., Chandra, A. and Bharagava, P., 2008. "Finite Element Analysis of Concrete Columns Confined with FRP Sheets". Journal of Reinforced Plastics and Composites, 27(12), pp.13491373.

Chastre, C. and Silva, M.A.G., 2010. "Monotonic axial behavior and modelling of RC circular columns confined with CFRP". Engineering Structures, 32(8), pp.2268-2277.

Chellapandian, M., Prakash, S.S. and Rajagopal, A., 2018. "Analytical and finite element studies on hybrid FRP strengthened RC column elements under axial and eccentric compression". Composite Structures, 184, pp.234-248.

Choi, E., Chung, Y-S., Park, K. and Jeon, J-S., 2013. "Effect of steel wrapping jackets on the bond strength of concrete and the lateral performance of circular RC columns". Engineering Structures, 48, pp.43-54.

Cui, C. and Sheikh, S.A., 2010a. "Analytical Model for Circular Normal- and High-Strength Concrete Columns Confined with FRP". Journal of Composites for Construction, 14(5), pp.562-572.

Cui, C. and Sheikh, S.A., 2010b. "Experimental Study of Normal- and High-Strength Concrete Confined with Fiber-Reinforced Polymers". Journal of Composites for Construction, 14(5), pp.553-561.

Cusson, D. and Paultre, P., 1995. "Stress-Strain Model for Confined High-Strength Concrete". Journal of Structural Engineering, 121(3), pp.468-477.

Daugevičius, M. Valinovis, J. Beinaravičius, A., Skuturna, T. and Budvytis, M., 2013. "Experimental Investigation of the Load Carrying Capacity of Eccentrically Loaded Reinforced Concrete Elements Strengthened with CFRP". Procedia Engineering, 57, pp.232-237.

El-Hacha, R., Green, M.F. and Wight, G.R., 2010. "Effect of Severe Environmental Exposures on CFRP Wrapped Concrete Columns". Journal of Composites for Construction, 14(1), pp.83-93.

Fam, A., Flisak, B. and Rizkalla, S., 2003. "Experimental and analytical modeling of concrete-filled fiber-reinforced polymer tubes subjected to combined bending and axial loads". ACI Structural Journal, 100(4), pp.499-509.

Fam, A.Z. and Rizkalla, S.H., 2001. "Confinement model for axially loaded concrete confined by circular fiber-reinforced polymer tubes". ACI Structural Journal, 98(4), pp.451-461.

Faustino, P. and Chastre, C., 2015. "Analysis of load-strain models for RC square columns confined with CFRP". Composites Part B: Engineering, 74, pp.23-41.

Faustino, P., Chastre, C. and Paula, R., 2014. "Design model for square RC columns under compression confined with CFRP". Composites Part B: Engineering, 57, pp.187-198.

Feng, P., Lu, X.Z. and Ye, L.P., 2002. "Experimental research and finite element analysis of square concrete columns confined by FRP sheets under uniaxial compression". 17th Australasian Conference on the Mechanics of Structures and Materials. Gold Coast, Australia, pp. 60-65. 
Garyfalia G. Triantafyllou; Theodoros C. Rousakis; and Athanasios I. Karabinis, 2015. "Axially Loaded Reinforced Concrete Columns with a Square Section Partially Confined by Light GFRP Straps". Journal of Composites for Construction, 17(6), pp.1-9.

Garzón-Roca, J., Adam, J.M. and Calderón, P.A., 2011. "Behaviour of RC columns strengthened by steel caging under combined bending and axial loads". Construction and Building Materials, 25(5), pp.2402-2412.

Ghali, K., Rizkalla, S.H., Kassem, M.A., Fawzy, T.M. and Mahmoud, M.H., 2003. "FRP-Confined Circular Columns under small Eccentric Loading". Proceedings of the Fifth Alexandria International Conference on Structural and Geotechnical Engineering, Alexandria, Egypt, December, pp.20-22.

Hadi, M.N.S., 2009. "Behaviour of eccentric loading of FRP confined fibre steel reinforced concrete columns". Construction and Building Materials, 23(2), pp.1102-1108.

Hadi, M.N.S. and Li, J., 2004. "External reinforcement of high strength concrete columns". Journal of Composite Structures, 65(3-4), pp.279-287.

Hajsadeghi, M., Alaee, F.J. and Shahmohammadi, A., 2011. "Investigation on Behaviour of Square/Rectangular Reinforced Concrete Columns Retrofitted with FRP Jacket". Journal of Civil Engineering and Management, 17(3), pp.400-408.

Hollaway, L.C. and Teng, J.G., 2008. Strengthening and Rehabilitation of civil infrastructures using Fibre-Reinforced Polymer (FRP) composites., Elsevier.

Hollaway, L.C., 2010. "A review of the present and future utilisation of FRP composites in the civil infrastructure with reference to their important in-service properties". Construction and Building Materials, 24(12), pp.2419-2445.

Hosseinpour, F. and Abbasnia, R., 2014. "Experimental investigation of the stress-strain behavior of FRP confined concrete prisms". Advances in Concrete Construction, 2(3), pp.177-192.

Howie, I. and Karbhari, V.M., 1995. "Effect of Tow Sheet Composite Wrap Architecture on Strengthening of Concrete Due to Confinement: I-Experimental Studies". Journal of Reinforced Plastics and Composites, 14(9), pp.1008-1030.

$\mathrm{Hu}$, B., Wang, J. and Li, G., 2011. "Numerical simulation and strength models of FRP-wrapped reinforced concrete columns under eccentric loading". Construction and Building Materials, 25(5), pp.2751-2763.

Ilki, A., Peker, O., Karamuk, E., Demir, C. and Kumbasar, N., 2008. "FRP Retrofit of Low and Medium Strength Circular and Rectangular Reinforced Concrete Columns". Journal of Materials in Civil Engineering, 20(2), pp.169-188.

Ilki, A. and Kumbasar, N., 2003. "Compressive Behaviour of Carbon Fibre Composite Jacketed Concrete with Circular and Non-Circular Cross-Sections". Journal of Earthquake Engineering, 7(3), pp.381-406. 
Jian C. Lim and Togay Ozbakkaloglu, 2014. "Design model for FRP-confined normal- and highstrength concrete square and rectangular columns". Magazine of Concrete Research, 66(20), pp.1020-1035.

Julio, E.N.B.S. and Branco, F., 2008. "Reinforced Concrete Jacketing-Interface Influence on Cyclic Loading Response". ACI Structural Journal, 105(4), pp.471-477.

Kaish, A.B.M.A. Alam, M.R., Jamil, M., Zain, M.F.M. and Wahed, M.A., 2012. "Improved ferrocement jacketing for restrengthening of square RC short column". Construction and Building Materials, 36, pp.228-237.

Karabinis, A.I., Rousakis, T.C. and Manolitsi, G.E., 2008. "3D Finite-Element Analysis of Substandard RC Columns Strengthened by Fiber-Reinforced Polymer Sheets". Journal of Composites for Construction, 12(5), pp.531-540.

Karbhari, V.M. and Eckel II, D.A. 1994. "Effect of Cold Regions Climate on Composite Jacketed Concrete Columns". Journal of Cold Regions Engineering, 8(3), pp.73-86.

Karbhari, V.M. and Gao, Yanqiang., 1997. "Composite Jacketed Concrete under Uniaxial Compression- Verification of Simple Design Equations". Journal of Materials in Civil Engineering, (November), pp.185-193.

Kumutha, R., Vaidyanathan, R. and Palanichamy, M.S., 2007. "Behaviour of reinforced concrete rectangular columns strengthened using GFRP". Cement and Concrete Composites, 29(8), pp.609-615.

Lai, M.H. and Ho, J.C.M., 2015. "Axial strengthening of thin-walled concrete-filled-steel-tube columns by circular steel jackets". Thin-Walled Structures, 97, pp.11-21.

Laine, D.P., 2004. Effect of axial preloads on confined concrete, Thesis (M.A.Sc.)--University of Toronto.

Lam, L. and Teng, J.G., 2004. "Ultimate Condition of Fiber Reinforced Polymer-Confined Concrete". Journal of Composites for Construction, 8(6), pp.539-548.

Lam, L. and Teng J.G., 2003a. "Design-oriented Stress-Strain Model for FRP confined concrete". Construction and Building Materials, 17(6-7), pp.471-489.

Lam, L. and Teng J.G., 2003b. "Design-oriented Stress-Strain Model for FRP-confined Concrete in Rectangular Columns". Journal of Reinforced Plastics and Composites, Vol. 22, No. 13, 22(13), p.1149-1186pp.

L. Lam; J.G Teng, 2002. "Strength Models for Fiber-Reinforced Plastic-Confined Concrete". Journal of Structural Engineering, 128(5), p.612.

Li, J. and Hadi, M.N.S., 2003. "Behaviour of externally confined high-strength concrete columns under eccentric loading". Journal of Composite Structures, 62(2), pp.145-153.

Lin, G. and Teng, J.G., 2017. "Three-Dimensional Finite-Element Analysis of FRP-Confined Circular Concrete Columns under Eccentric Loading". Journal of Composites for Construction, 21(4), 
p.4017003.

lmran, I. and Pantazopoulou, S. J., 1996. "Experimental Study of Plain Concrete under Triaxial Stress". ACI Materials Journal, 93(6), pp.589-601.

De Lorenzis, L. and Tepfers, R., 2003. "Comparative Study of Models on Confinement of Concrete Cylinders with Fiber-Reinforced Polymer Composites". Journal of Composites for Construction, 7(3), pp.219-237.

M.N.S Hadi; I.B.R Widiarsa, 2012. "Axial and Flexural Performance of Square RC Columns Wrapped with CFRP under Eccentric Loading". Journal of Composites for Construction, 16 (December), pp.640-649.

Maaddawy, T. El, 2009. "Strengthening of Eccentrically Loaded Reinforced Concrete Columns with Fiber-Reinforced Polymer Wrapping System: Experimental Investigation and Analytical Modeling". Journal of Composites for Construction, 13(1), pp.13-24.

Malvar, L.J., Morrill, K.B. and Crawford, J.E., 2004. "Numerical Modeling of Concrete Confined by Fiber-Reinforced Composites". Journal of Composites for Construction, 8(4), pp.315-322.

Mander, J.B., Priestley, M.J.N. and R.Park, 1988. "Theoretical Stress Strain Model for Confined Concrete". Journal of Structural Engineering, 114(8), pp.1804-1825.

Marques, P.F. and Chastre, C., 2012. "Performance analysis of load-strain models for circular columns confined with FRP composites". Composite Structures, 94(11), pp.3115-3131.

Masia, M.J., Gale, T.N. and Shrive, N.G., 2004. "Size effects in axially loaded square-section concrete prisms strengthened using carbon fibre reinforced polymer wrapping". Canadian Journal of Civil Engineering, 31(1), pp.1-13.

Matthys, S., Toutanji, H., Audenaert, K. and Taerwe, L., 2005. "Axial load behavior of large-scale columns confined with fiber-reinforced polymer composites". ACI Structural Journal, 102(2), pp. $258-267$.

Matthys, S., 2000. Structural behaviour and design of concrete members strengthened with externally bonded FRP reinforcement. $\mathrm{PhD}$ Thesis, Ghent University.

Matthys, S., Toutanji, H. and Taerwe, L., 2006. "Stress-Strain Behavior of Large-Scale Circular Columns Confined with FRP Composites". Structural Engineering, 132(1), pp.123-133.

Mirmiran, A., Shahawy, M., Samaan, M., El Echary, H., Mastrapa, J.C. and Pico, O., 1998. "Effect of Column Parameters on FRP-Confined Concrete". Journal of Composites for Construction, 2(4), pp.175-185.

Mirmiran, A. and Shahawy, M., 1997. "Behaviour of Concrete Columns Confined by Fiber Composites". Journal of Structural Engineering, 123(5), pp.583-590.

Mirmiran, A., Zagers, K. and Yuan, W., 2000. "Non-linear finite element modeling of concrete confined by fiber composites". Journal of Finite Element in Analysis and Design, 35, pp.79-96.

Moshiri, N., Hosseini, A. and Mostofinejad, D., 2015. "Strengthening of RC columns by longitudinal 
CFRP sheets: Effect of strengthening technique". Construction and Building Materials, 79, pp.318-325.

Mostofinejad, D. and Saadatmand, H., 2010. "A Procedure for Predicting the Behavior of FRP Confined Concrete Using the FE Method". Scientia Iranica Transaction a-Civil Engineering, 17(6), pp.471-481.

Nanni, A. and Bradford, N.M., 1995. "FRP jacketed concrete under uniaxial compression". Construction and Building Materials, 9(2), pp.115-124.

Ozbakkaloglu, T., Lim, J.C. and Vincent, T., 2013. "FRP-confined concrete in circular sections : Review and assessment of stress-strain models". Engineering Structures, 49, pp.1068-1088.

Ozbakkaloglu, T. and Oehlers, D.J., 2008. "Concrete-Filled Square and Rectangular FRP Tubes under Axial Compression". Journal of Composites for Construction, 12(4), pp.469-477.

Parghi, A. and Alam, M.S., 2018. "A review on the application of sprayed-FRP composites for strengthening of concrete and masonry structures in the construction sector". Composite Structures, 187, pp.518-534.

Parghi, A. and Alam, M.S., 2016. "Seismic behavior of deficient reinforced concrete bridge piers confined with FRP - A fractional factorial analysis". Engineering Structures, 126, pp.531-546.

Parghi, A. and Alam, M.S., 2017. "Seismic collapse assessment of non-seismically designed circular RC bridge piers retrofitted with FRP composites". Composite Structures, 160, pp.901-916.

Park, R. and Paulay, T., 1975. Reinforced Concrete Structures.John Wiley \& Sons., New York, U.S.A.

Pessiki, S., Harries, K.A., Kestner, J.T., Sause, R. and Ricles, J.M., 2001. "Axial Behaviour of Reinforced Concrete Columns Confined with FRP Jackets". Journal of Composites for Construction, 5(November), pp.237-245.

Richart, F.E., Brandtzaeg, A. and Brown, R.L., 1928. "A Study of The Failure of Concrete Under Combined Compressive Stresses". University of Illinois Bulletin, XXVI(12), p.110.

Rodrigues, C.C. and Silva, M.G., 2001. "Experimental Investigation of CFRP Reinforced Concrete Columns under Uniaxial Cyclic Compression". FRPRCS-5, 5th International Conference on Fibre Reinforced Plastics for Reinforced Concrete Structures. C. Burgoyne. Cambridge, UK: Thomas Telford Ltd, pp. 784-792.

Rodrigues, C.C. and Silva, M.G., 2001. "The behaviour of GFRP reinforced concrete columns under monotonic and cyclic axial compression". CCC2001, Composites in Construction. Porto: A. A. Balkema, pp. 245-250.

Saadatmanesh, H., Ehsani, M.R. and Li, M.W., 1994. "Strength and ductility of concrete columns externally reinforced with fiber composite straps". ACI Structural Journal, 91(4), pp.434-447.

Saafi, M., Toutanji, H.A. and Li, Zongjin., 1999. "Behavior of concrete columns confined with fiber reinforced polymer tubes". ACI Materials Journal, 96(4), pp.500-509.

Sadeghian, P., Rahai, A.R. and Ehsani, M.R., 2010. "Experimental Study of Rectangular RC Columns 
Strengthened with CFRP Composites under Eccentric Loading". Journal of Composites for Construction, 14(4), pp.443-450.

Samaan, M., Mirmiran, A. and Shahawy, M., 1998. "Model of Concrete Confined by Fiber Composites". Journal of Structural Engineering, 124(9), pp.1025-1031.

SeismoStruct, 2015. "A computer program for static and dynamic nonlinear analysis of framed structures". V, 7.06. Available at: http://www.seismosoft.com.

Sezen, H. and Miller, E.A., 2011. "Experimental Evaluation of Axial Behavior of Strengthened Circular Reinforced-Concrete Columns". Journal of Bridge Engineering, 16(2), pp.238-247.

Shehata, I.A.E.M., Carneiro, L.A.V. and Shehata, L.C.D., 2001. "Strength of short concrete columns confined with CFRP sheets". Materials and Structures, 35(245), pp.50-58.

Sheikh, S.A., Jaffry, S.A.. and Cui, C., 2007. "Investigation of glass-fibre-reinforced-polymer shells as formwork and reinforcement for concrete columns". Canadian Journal of Civil Engineering, 34(3), pp.389-402.

Siddiqui, N.A., Alsayed, S.H., Al-Salloum, Y.A., Iqbal, R.A. and Abbas, H., 2014. "Experimental investigation of slender circular RC columns strengthened with FRP composites". Construction and Building Materials, 69, pp.323-334.

Silva, M.A.G. and Rodrigues, C.C., 2006. "Size and Relative Stiffness Effects on Compressive Failure of Concrete Columns Wrapped with Glass FRP". Journal of Materials in Civil Engineering, 18(3), pp.334-342.

Spoelstra, M.R. and Monti,Giorgio., 1999. "FRP-Confined Concrete Model". Composites for Construction, 3(August), pp.143-150.

Tasdemir, M.A., Tasdemir, C., Akyüz, S., Jefferson,A.D., Lydon,F.D. and Barr,B.I.G., 1998. "Evaluation of strains at peak stresses in concrete: A three-phase composite model approach". Cement and Concrete Composites, 20(4), pp.301-318.

Teng, J.G., Chen, J.F., Smith, S.T. and Lam, L., 2002. FRP Strengthened RC Structures L. Wiley, John and Sons, ed., West Sussex, England:

Togay Ozbakkaloglu, Jian C. Lim, 2013. "Axial compressive behavior of FRP-confined concrete : Experimental test database and a new design-oriented model". Composites Part B, 55, pp.607634.

Toutanji, H., 1999. "Stress-Strain Characteristic of Concrete Columns Externally Confined with Advance Fiber Composite Sheets". ACI Materials Journal, 96 (May-June), pp.397-404.

Toutanji, H., Han, M., Gilbert, J. and Matthys, S., 2010. "Behavior of Large-Scale Rectangular Columns Confined with FRP Composites". Journal of Composites for Construction, 14(1), pp.62-71.

Toutanji, H. and Balaguru, P., 1998. "Durability Characteristics of Concrete Columns Wrapped with FRP Tow Sheets". Journal of Materials in Civil Engineering, 10(1), pp.52-57. 
Vandoros, K.G. and Dritsos, S.E., 2008. "Concrete jacket construction detail effectiveness when strengthening RC columns". Construction and Building Materials, 22(3), pp.264-276.

Vandoros, K.G. and Dritsos, S.E., 2006. "Interface treatment in shotcrete jacketing of reinforced concrete columns to improve seismic performance". Structural Engineering and Mechanics, 23(1), pp.43-61.

Vincent, T. and Ozbakkaloglu, T., 2014. "Compressive Behavior of Prestressed High-Strength Concrete-Filled Aramid FRP Tube Columns: Experimental Observations". Journal of Composites for Construction, pp.1-13.

Wang, L.M. and Wu, Y.F., 2008. "Effect of corner radius on the performance of CFRP-confined square concrete columns: Test". Engineering Structures, 30(2), pp.493-505.

Wang, W., Sheikh, M.N., Hadi, M.N.S., Gao, D. and Chen, G., 2017. "Behaviour of concrete-encased concrete-filled FRP tube (CCFT) columns under axial compression". Engineering Structures, 147, pp.256-268.

Wei, Y.Y. and Wu, Y.F., 2012. "Unified stress-strain model of concrete for FRP-confined columns". Construction and Building Materials, 26(1), pp.381-392.

Widiarsa, I.B.R. and Hadi, M.N.S., 2013. "Performance of CFRP Wrapped Square Reinforced Concrete Columns Subjected to Eccentric Loading". Procedia Engineering, 54, pp.365-376.

Willam, K. and Warnke, E., 1975. "Constitutive model for the triaxial behavior of concrete". Proceedings of International Association for Bridge and Structural Engineering 19, pp.1-30.

Wu, G., Lü, Z.T. and Wu, Z.S., 2006. "Strength and ductility of concrete cylinders confined with FRP composites". Construction and Building Materials, 20(3), pp.134-148.

$\mathrm{Wu}, \mathrm{G} ., \mathrm{Wu}, \mathrm{Z} . \mathrm{S}$. and Lu, Z.T., 2007. "Design-oriented stress-strain model for concrete prisms confined with FRP composites". Construction and Building Materials, 21, pp.1107-1121.

Wu, H.-L., Wang, Y.-F., Yu, Liu.and Li, X.-R., 2009. "Experimental and Computational Studies on High-Strength Concrete Circular Columns Confined by Aramid Fiber-Reinforced Polymer Sheets". Journal of Composites for Construction, 13(May 2011), pp.125-134.

Wu, Y.-F. and Cao, Y.-G., 2017. "Effect of Load Path on Behaviour of FRP-Confined Concrete". Journal of Composites for Construction, 21(4), p.4017014.

Wu, Y.-F. and Jiang, C., 2013. "Effect of load eccentricity on the stress-strain relationship of FRPconfined concrete columns". Composite Structures, 98, pp.228-241.

Wu, Yu-Fei. and Wei,Yang., 2014. "General Stress-Strain Model for Steel- and FRP-Confined Concrete". Journal of Composites for Construction, pp.1-14.

Xiao, Y. and Wu, H., 2003. "Retrofit of Reinforced Concrete Columns Using Stiffened Steel Jackets". Journal of Structural Engineering, 129(6), pp.725-732.

Xiao, Y. and Wu, H., 2003. "Compressive Behaviour of Concrete Confined by Various Types of FRP". Journal of Reinforced Plastics and Composites, 22(13), pp.1187-1201. 
Youssef, M.N., Feng, M.Q. \& Mosallam, A.S., 2007. "Stress-strain model for concrete confined by FRP composites". Composites Part B: Engineering, 38(July 2006), pp.614-628.

Yu, T., Teng, J.G., Wong, Y.L. and Dong, S.L., 2010. "Finite element modeling of confined concreteI: Drucker-Prager type plasticity model". Engineering Structures, 32(3), pp.665-679.

Zeng, Junjie., Guo, Yongchang., Li, Lijuan. and Chen, W., 2018." Behaviour and Three-Dimensional Finite Element Modeling of Circular Concrete Columns Partially Wrapped with FRP Strips". Polymers, 10(3), p.253.

Zhou, Y.-W. and Wu, Y.-F., 2012. "General model for constitutive relationships of concrete and its composite structures". Composite Structures, 94(2), pp.580-592. 
Table-1. Level of factors for nonlinear pushover analysis (Parghi and Alam, 2016)

\begin{tabular}{lllll}
\hline S/N & Factors/parameters & Level & \\
\cline { 3 - 5 } & & Low (-1) & Medium (0) & High (+1) \\
\hline 1. & Compressive strength of concrete, $f_{c}^{\prime}(\mathrm{MPa})$ & 25 & 30 & 35 \\
2. & Yield strength of steel, $f_{y}(\mathrm{MPa})$ & 250 & 300 & 350 \\
3. & Longitudinal steel reinforcement ratio, $\rho_{l}(\%)$ & 1.5 & 2 & 2.5 \\
4. & Spacing of stirrups, $s(\mathrm{~mm})$ & 300 & 250 & 200 \\
5. & Axial load, $P(\%)$ & 5 & 10 & 15 \\
6. & Shear span-depth ratio $(H / d)$ & 3 & 5 & 7 \\
7. & CFRP layers $(n)$ & 1 & 2 & 3 \\
\hline
\end{tabular}



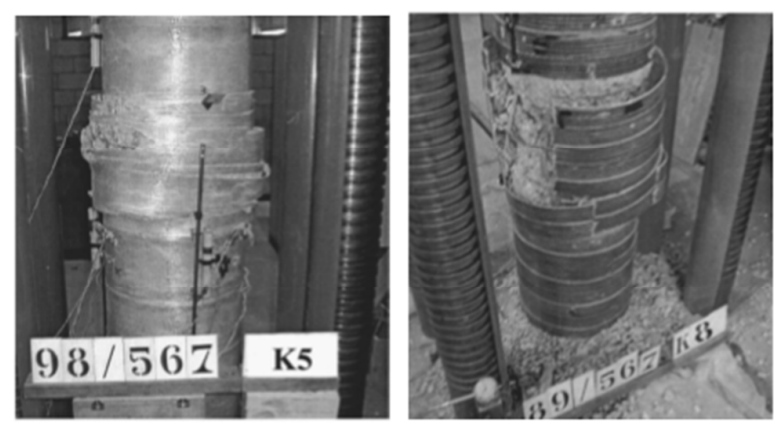

Figure-1. Failure of GFRP and HFRP fully wrapped column (Matthys et al., 2006)

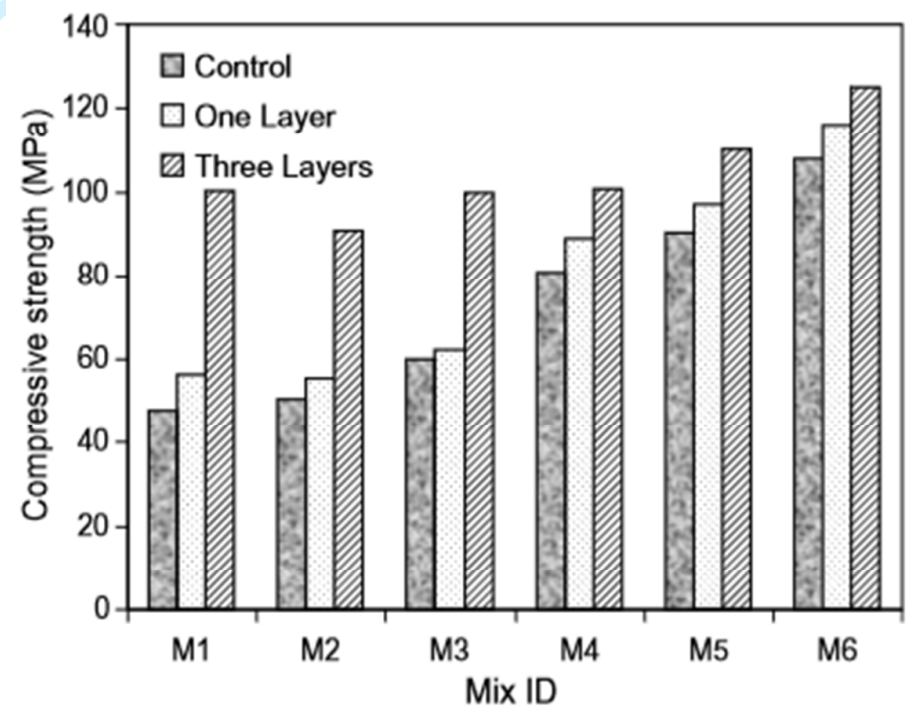

Figure-2. Variation of compressive strength gain with number of FRP layers (Almusallam, 2007)

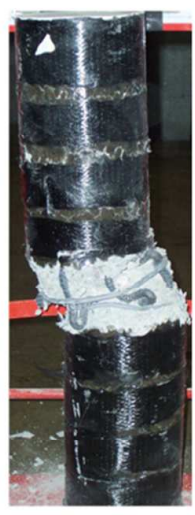

(a)

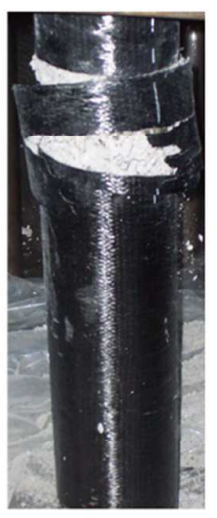

(b)

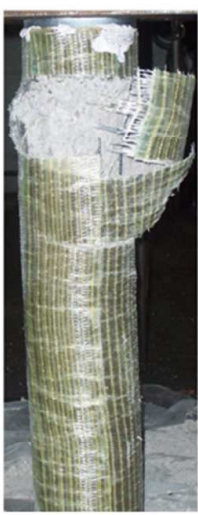

(c)

Figure-3. Columns strengthened using (a) CFRP strips (b) CFRP sheet (c) GFRP sheet (Sezen and Miller, 2011) 


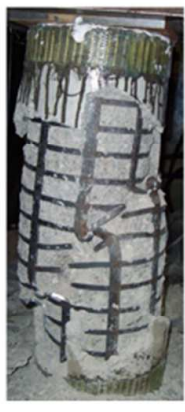

(a)

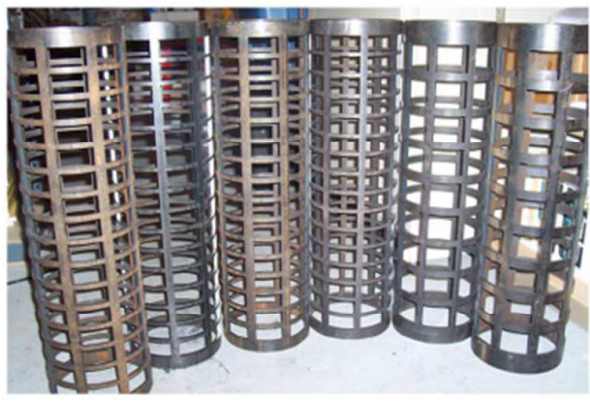

(b)

Figure-4. (a) Specimen jacketed with PCS reinforcement (b) PCS used for reinforcing concrete jackets (Sezen and Miller, 2011)

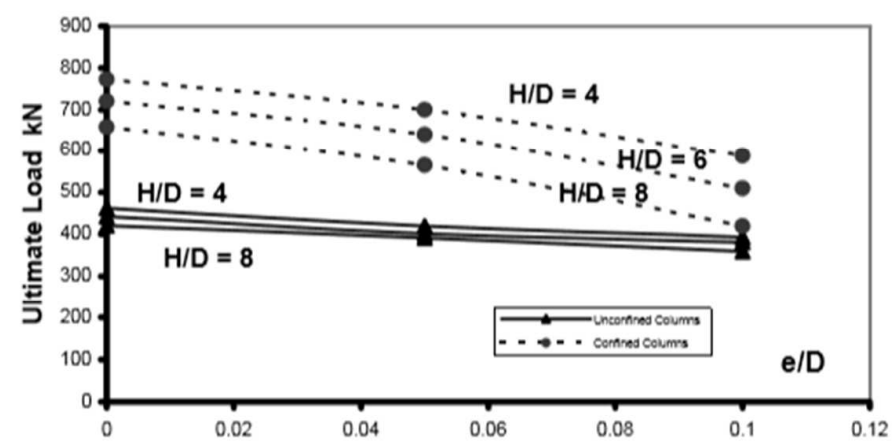

Figure-5. Influence of load eccentricity on ultimate load for confined and unconfined concrete cylinders (Ghali et al., 2003).
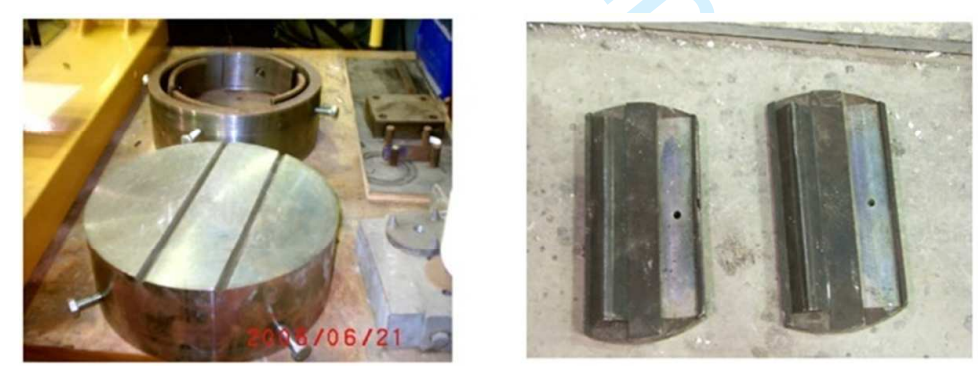

Figure-6. Loading caps for eccentric loads (Hadi, 2009) 


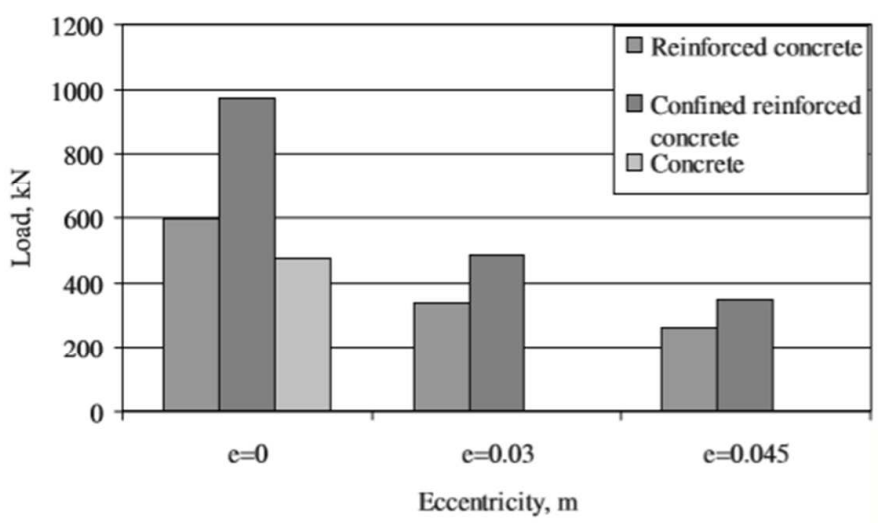

Figure-7. Variation of load carrying capacity with eccentricity (Daugevičius et al., 2013)

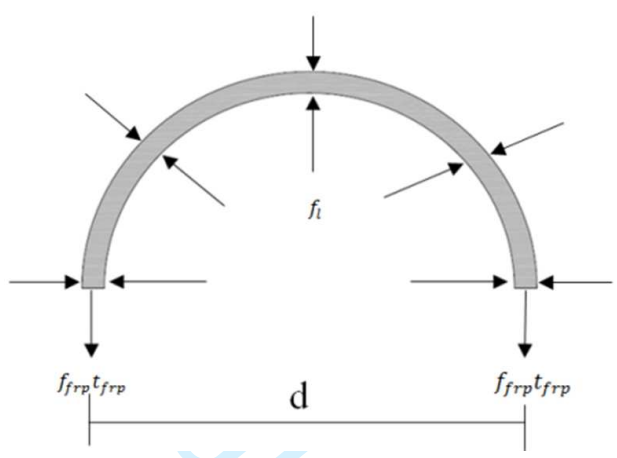

Figure-8. Confining action of FRP composites in circular concrete section

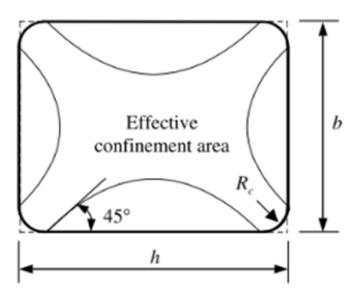

(a)

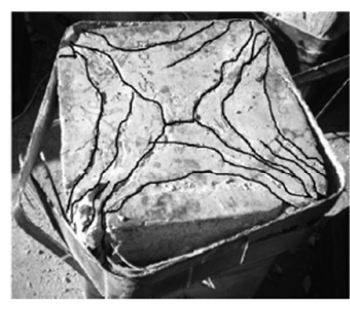

(b)

Figure-9. Confinement of concrete column with FRP jacket (a) Effectively confined concrete in rectangular column (Lam and Teng 2003b) (b) Dilated square column confined with carbon/epoxy jacket (Youssef et al., 2007) 


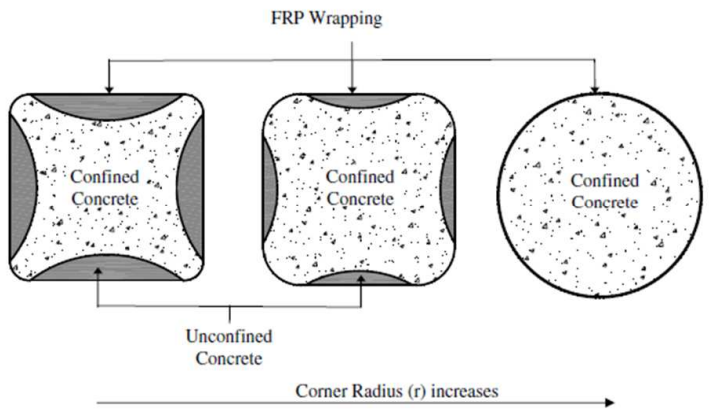

Figure-10. Effect of corner radius on confined concrete in square and cylindrical columns (AlSalloum, 2007)

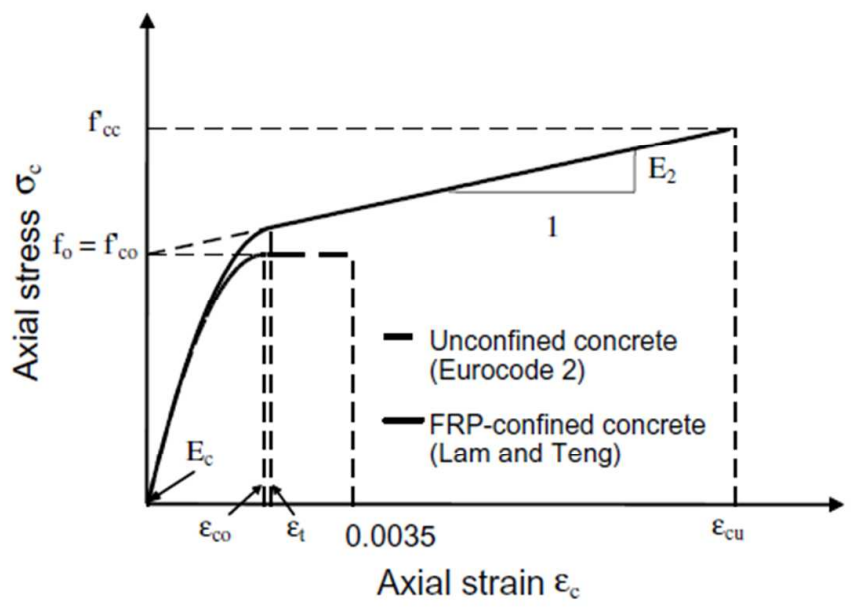

Figure-11. Lam and Teng's stress-strain model for FRP confined concrete (Lam and Teng, 2003b)

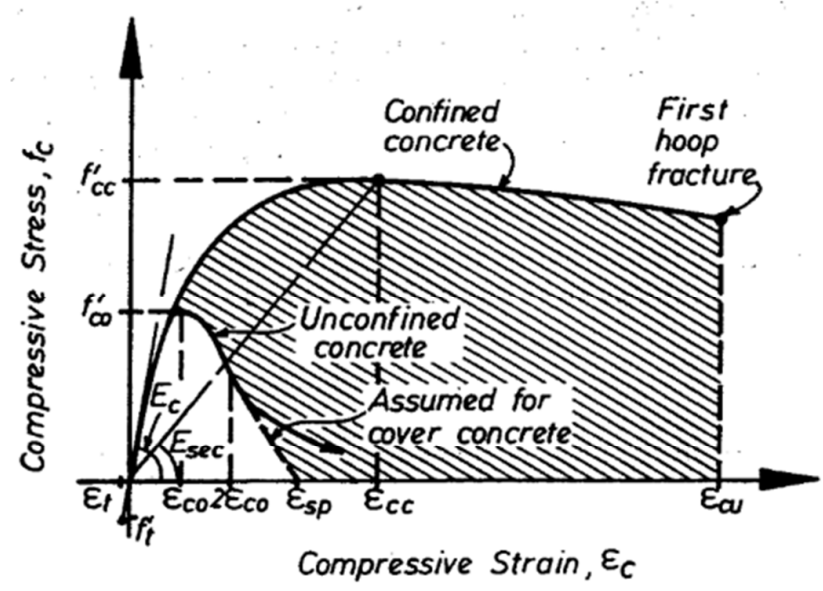

Figure-12. Stress-Strain Model for Monotonic Loading of Confined and Unconfined Concrete (Mander et al., 1988) 


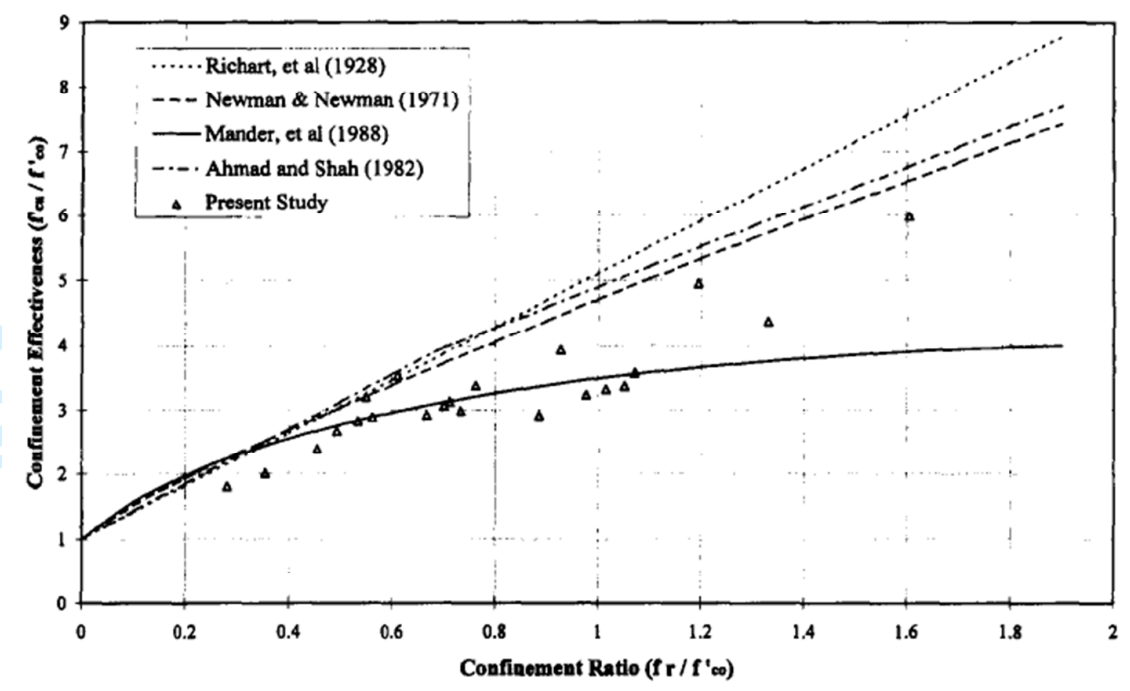

Figure-13. Confinement Effectiveness versus Confinement Ration (Mirmiran and Shahawy, 1997)

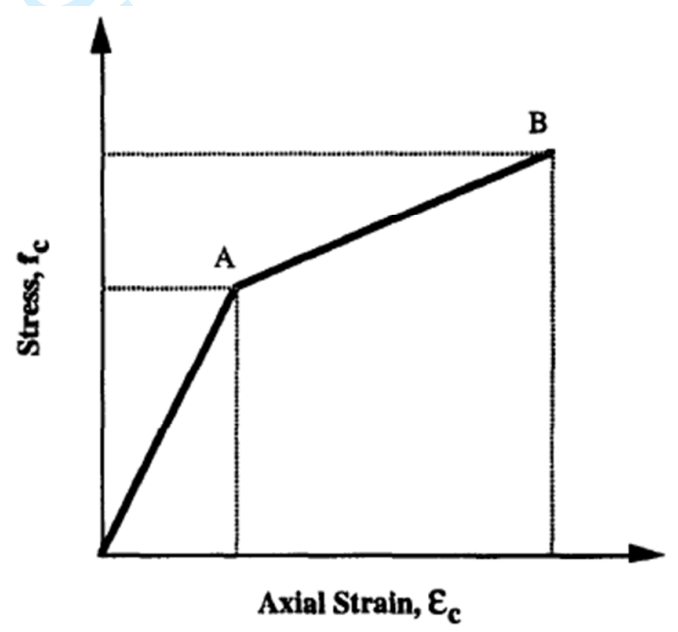

Figure-14. Characteristic Stress-Strain Response of Composite Jacketed Concrete under Uniaxial Compression (Karbhari and Gao, 1997) 


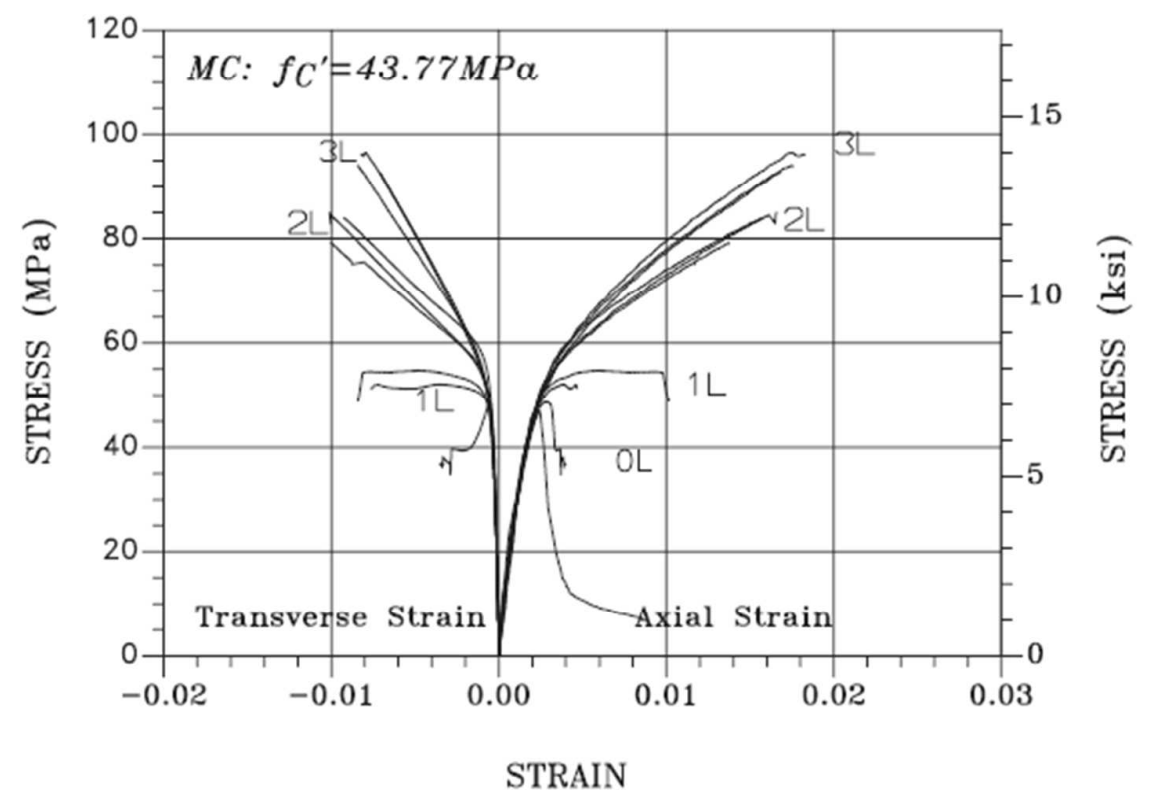

Figure-15. Axial stress-strain relationships for concrete with carbon fibre composite jackets (Xiao and $\mathrm{Wu}, 2003)$

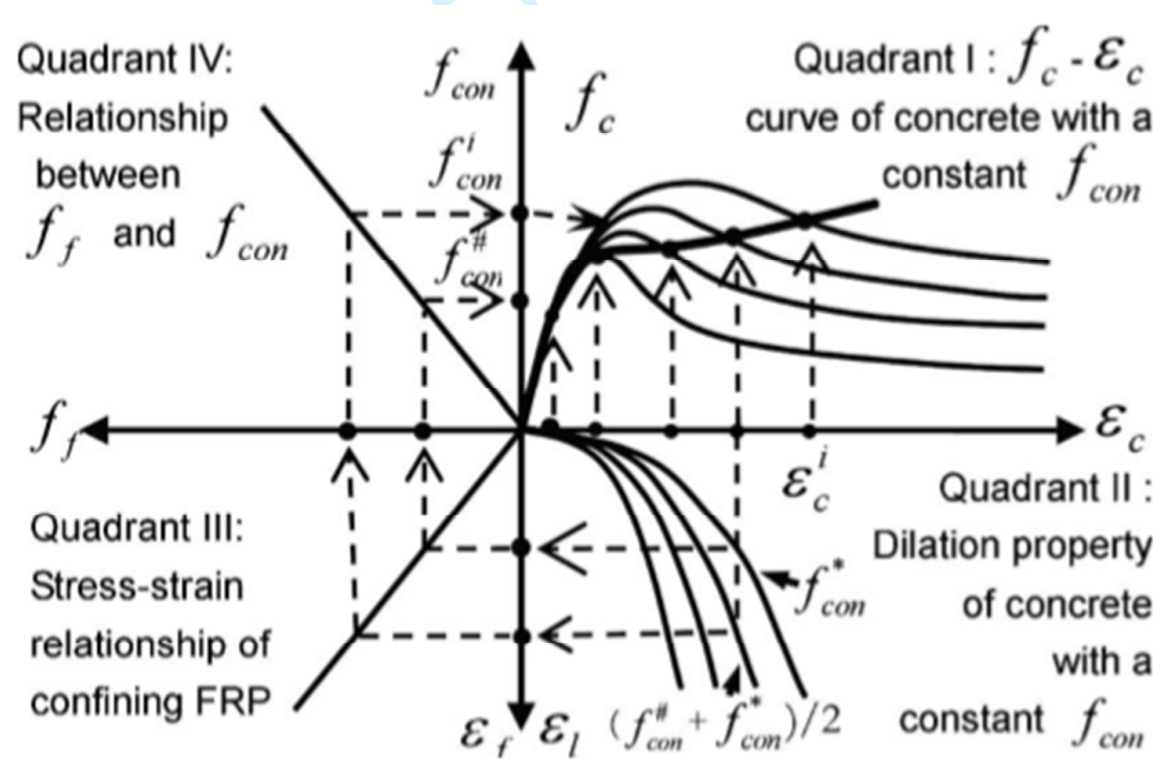

Figure-16. Four quadrants of relationships for developing a constitutive model (Cui \& Sheikh 2010a) 


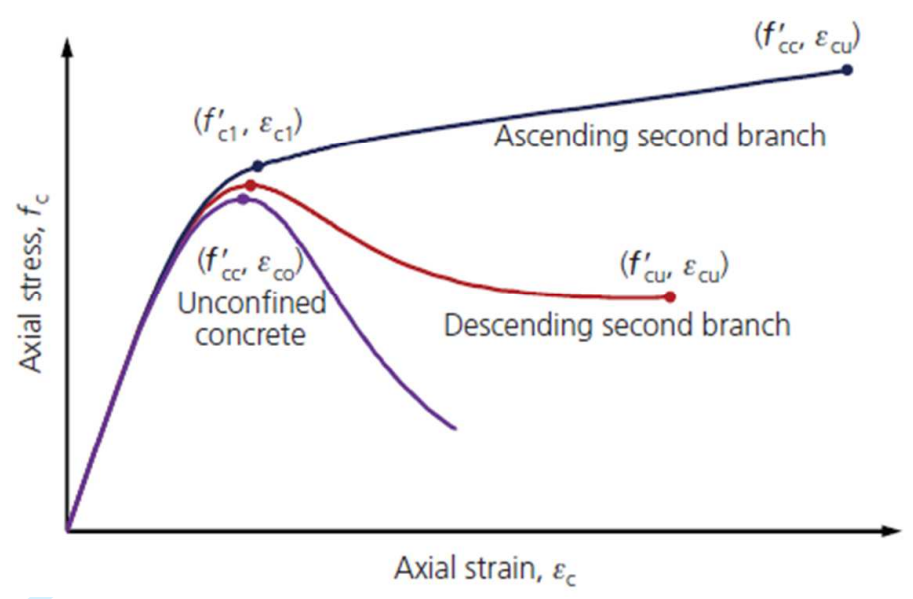

Figure-17. Axial stress-strain curve of unconfined concrete and FRP-confined concrete with ascending and descending second branches (Lim and Ozbakkaloglu, 2014)

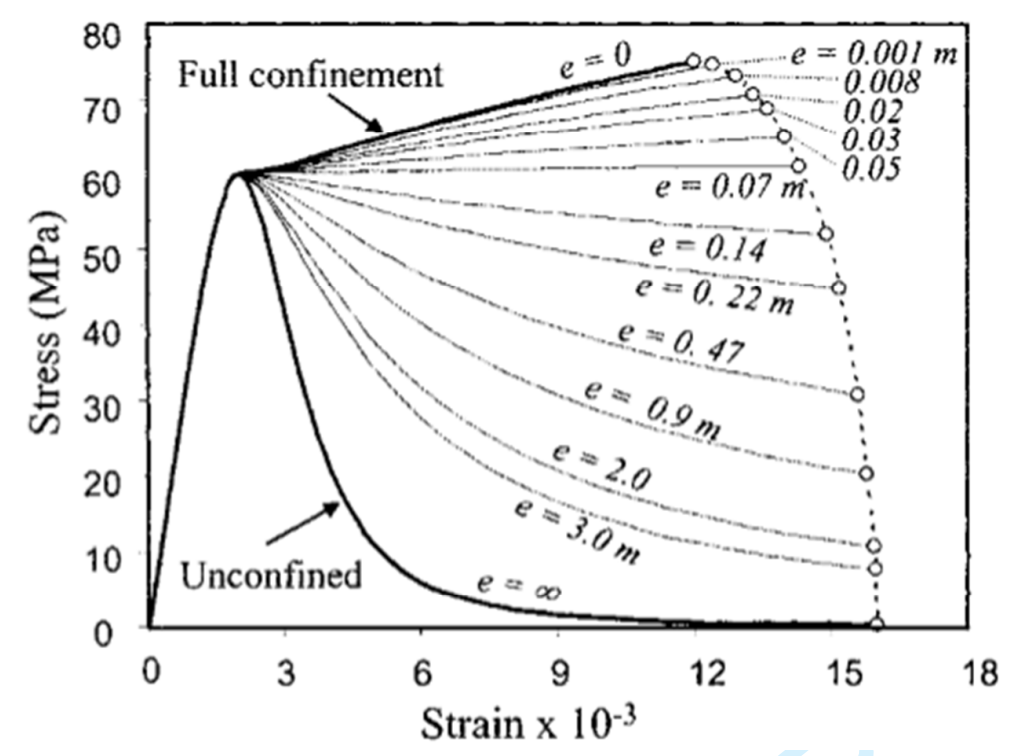

Figure-18. Stress-strain curve for FRP confined concrete under various load eccentricities (Fam et al., 2003)

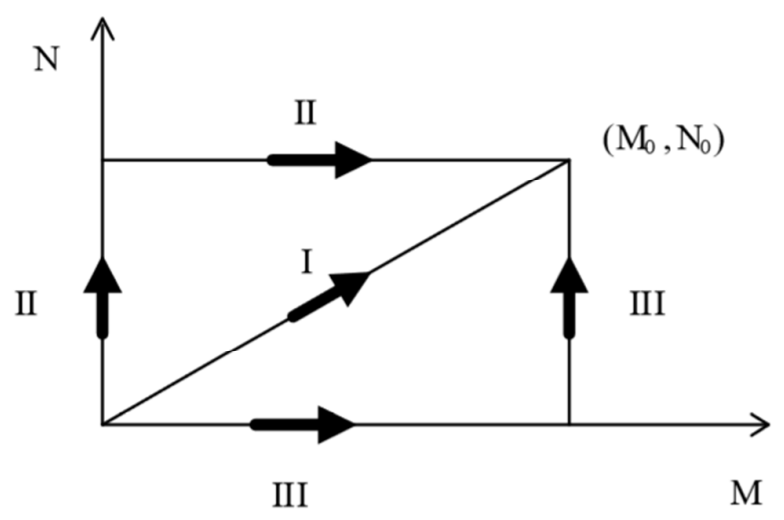

Figure-19. Definition of load paths for concrete columns (Cao et al. 2018) 


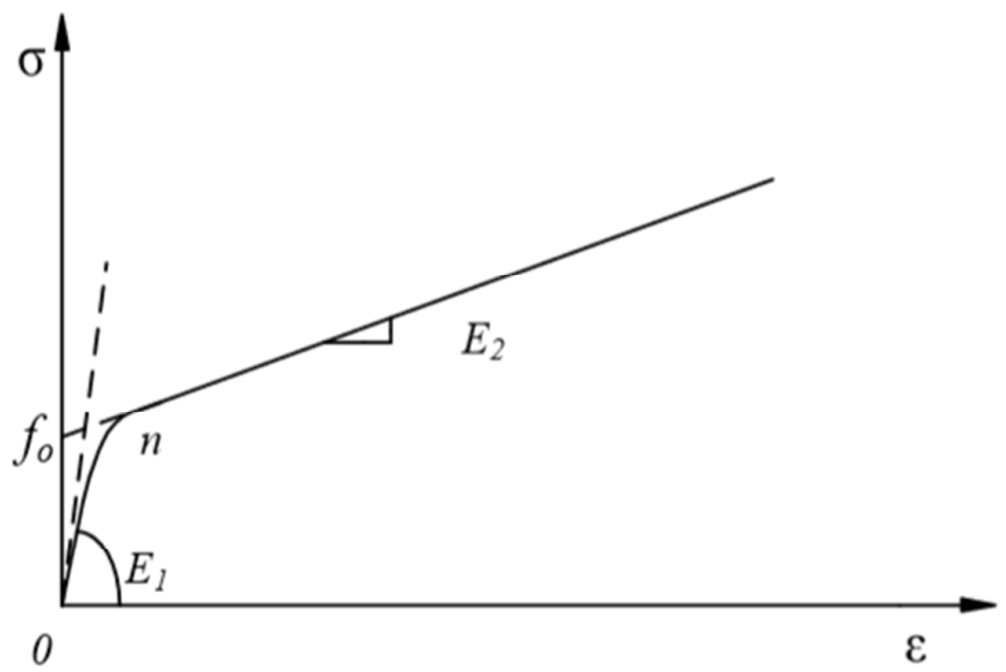

Figure-20. Stress-strain model for eccentrically loaded circular concrete columns confined with FRP (Cao et al. 2018)

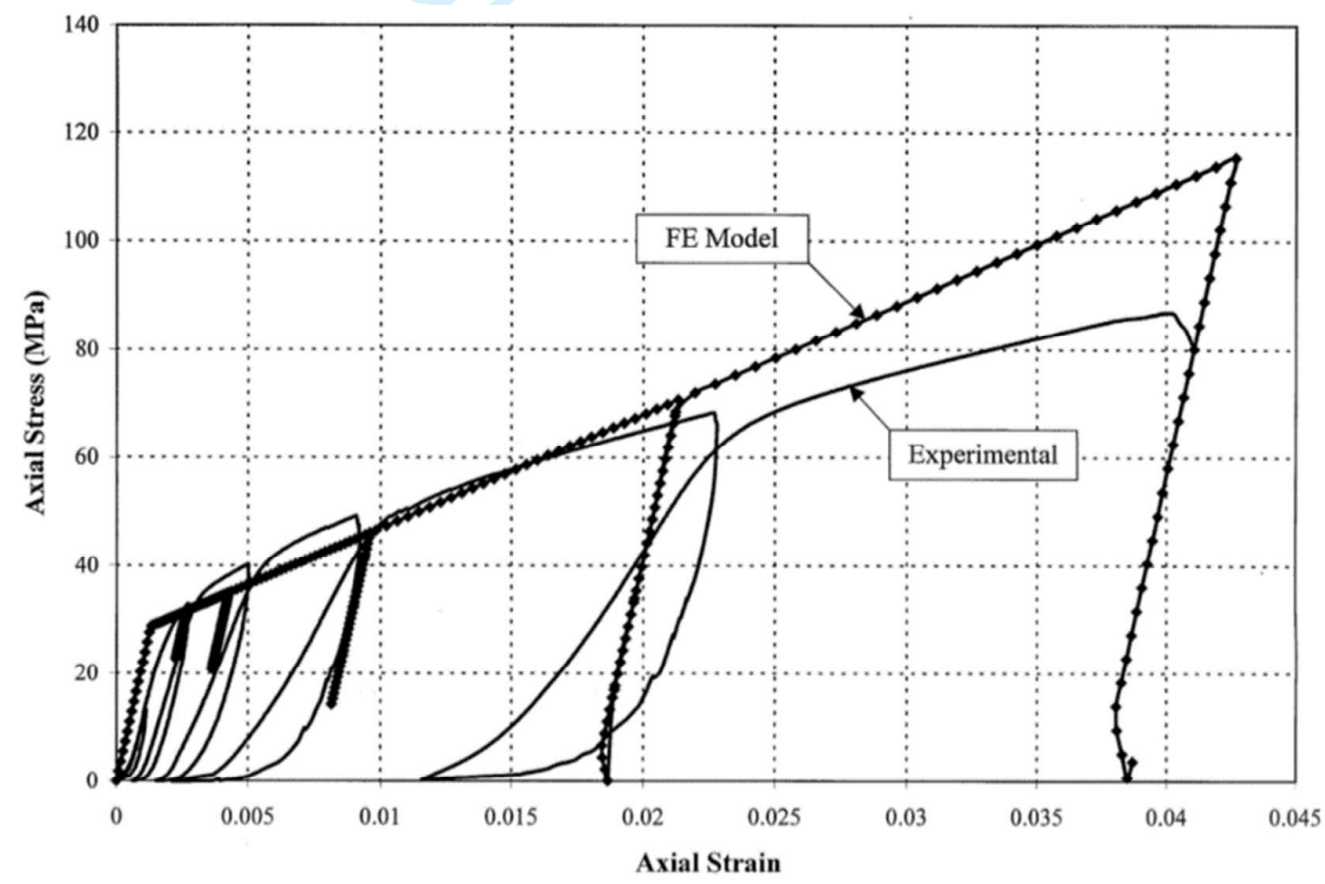

Figure-21. Comparison of predicted and experimental cyclic response of the columns (Mirmiran et al. 2000) 